\title{
LEGITIMACIÓN RELIGIOSA DE LA POÉTICA DE ARQUÍLOCO. LA INSCRIPCIÓN DE MNESIEPES*
}

\author{
Sebastián Eduardo Carrizo \\ CONICET-Universidad Nacional de Rosario
}

\begin{abstract}
RESUMO: Evidências dispersas e fragmentárias reunidas ao longo dos últimos séculos permitiram delinear os traços do culto que os habitantes da ilha de Paros, na Grécia, ofereceram a Arquíloco. A história deste culto, que parece ter-se estendido do ato mesmo das exéquias públicas do poeta (século VII a. C.) até a profanação do monumento funerário (século III d. C.), chegou aos nossos dias através de testemunhos literários, epigráficos e iconográficos. Porém, só a partir da descoberta da "Inscrição de Mnesiepes" em 1949 e a posterior "editio princeps" pôde-se postular uma reconstrução na íntegra da apoteose e da instauração do ritual. O objeto deste trabalho consiste em analisar a relação dialógica que se estabelece entre a obra poética e a instituição do culto heroico ao poeta.
\end{abstract}

PALAVRAS-CHAVE: Arquíloco; Inscrição de Mnesiepes; Iambos; Paros.

a "Inscripción de Mnesiepes",, hallada en dos bloques de mármol pertenecientes a un templo o recinto de carácter sacro construido

\footnotetext{
* El presente trabajo surge de un seminario doctoral dictado por el Dr. Richard Martin titulado "Religión Homérica: Poesía y Teología". Agradezco las sugerencias realizadas por el Dr. Martin y su estímulo para la presente publicación. Agradezco muy especialmente, también, a la Dra. Claudia Fernández (CONICET - UNLP) por el seguimiento y las continuas correcciones del artículo.

$\star \star$ carrizo_sebastian@hotmail.com

${ }^{1}$ La primera edición de la inscripción fue realizada por Kontoleon, N. M.

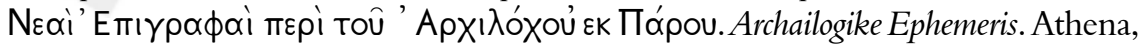
vol. XCI, p. 32-95, 1952. Posteriormente, editada con modificaciones por Peek, W.
} 
especialmente para honrar al poeta, ${ }^{2}$ contiene la transcripción de un conjunto de disposiciones rituales, narraciones orales y oráculos délficos que revelan cómo se configura el vínculo entre el plano de lo divino y el plano de lo humano en la instauración de la autoridad poética de Arquíloco. En efecto, el discurso popular, el discurso religioso, el discurso poético y el discurso histórico gestan un relato de consagración - Dichterweihe - mediante el cual el poeta es legitimado por la divinidad y esa misma divinidad encuentra una vía de reproducción ritual dentro de la comunidad. ${ }^{3}$

Específicamente, estos lazos se definen, por un lado, en el sustrato religioso que la poesía yámbica de Arquíloco conserva de antiguos misterios y creencias; y, por otro, en el surgimiento y expansión del relato que liga al poeta y a su poética, luego de su muerte, al universo de los discursos religiosos. Desde esta perspectiva, consideramos necesario llevar adelante una indagación sobre los temas cultuales que aparecen en la obra, lo cual nos permitiría determinar su relación, explícita en la "Inscripción de Mnesiepes", con los rituales dionisíacos y eleusinos. Indefectiblemente, este abordaje conducirá a centrarnos principalmente en el sympósion y en los componentes de la poesía

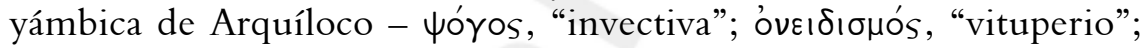

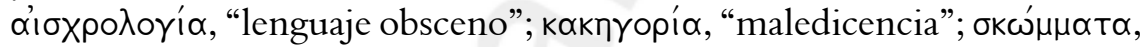

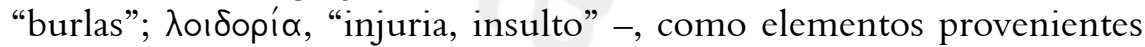
de los ritos relacionados con las festividades consagradas a Dioniso y a

Neues von Archilochos. Philologus. Berlin, vol. XCIX, p. 4-50, 1955. Nuevamente, corregida y reeditada por Kontoleon, N. M. Archiloque d'après la nouvelle inscription de Paros. L'Hellénisme contemporain. Athènes, ser. II, vol. X, p. 397-406, 1956a; Kontoleon, N. M. Zu den neuen Archilochos Inschriften. Philologus. Berlin, vol. C, p. 29-39, 1956b. Véase además, Kontoleon, N. M. Archilochos und Paros. Entretiens surl'Antiquité Classique - Archiloque. Fondation Hardt. Genéve, vol. X, p. 39-86, 1964. Para una completa documentación de la inscripción, junto con los distintos testimonios literarios, epigráficos e iconográficos véase Clay, D. Archilochos heros. The cult of poets in the Greek polis. Cambridge, Mass./London: Harvard University Press, 2004. Para los testimonios literarios y para la obra misma de Arquíloco: Tarditi, G. Archilochus. Roma: Edizioni dell'Ateneo, 1968. West, M. L. Iambi et elegi Graeci ante Alexandrum cantati, I. Oxford: University Press, 1989.

${ }^{2}$ La propia inscripción nos informa que el nombre asignado al recinto fue el de

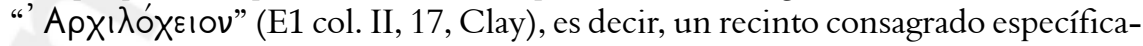
mente a la honra del poeta.

${ }^{3}$ Cf. Kambylis, A. Zur "Dichterweihe" des Archilochos. Hermes. Wiesbaden, vol. XCI, t. 2, p. 129-150, 1963. 
Deméter. ${ }^{4}$ En este sentido, la performance yámbica de Arquíloco en su instancia de enunciación poética tendría la función de actualización, dentro de su mundo de recepción, del complejo universo simbólico que constituye el ámbito de lo religioso. ${ }^{5}$

${ }^{4}$ Sobre el sustrato religioso del yambo y sobre el sympósion del s. VII a. C. como espacio ritual, nos gustaría recordar que, a partir de los estudios sobre la performance y las teorías de la recepción, las categorías de metro y contenido para la distinción de los géneros poéticos en la Grecia arcaica comenzaron a perder relevancia frente al concepto de "ocasión"; cf. Dover, K. J. The poetry of Archilochos. Entretiens sur l'Antiquité Classique - Archiloque. Fondation Hardt. Genève, vol. X, p. 183-222, 1964; Calame, C. Réflexions sur les genres littéraires en Grèce archaïque. Quaderni Urbinati di Cultura Classica. Urbino, vol. XVII, p. 111-128, 1974; West, M. L. Studies in Greek elegy and iambus. Berlin/ New York: Walter de Gruyter, 1974; Fowler, R. L. The nature of early Greek lyric. Three preliminary studies. Toronto/ Buffalo/ London: University of Toronto Press, 1987. Específicamente, en relación a la poesía yámbica de Arquíloco, Dover afirmaba: This survey of terminology offers no grounds for doubting the conclusion which I drew from the community of ethos between the elegiacs and " $\alpha \mu \beta$ ol of Archilochos: no grounds for believing that he regarded them as different genres. It also leaves open the possibility that he used the word" " $\alpha \mu$ Bo with reference to all the forms of poem which he composed, their common characteristic being not their metre or language but the type of occasion for which they were composed - their 'social context', in fact.; cf. Dover, op. cit., p. 189. Una década más tarde, West retoma la hipótesis de Dover: I believe the most fruifful line of inquiry to be that suggested by a remark of Dover's (op. cit.), that the common characteristic of iambi might have been the type of occasion for which they were composed; cf. West, op. cit., 1974, p. 23. Aunque la concepción propuesta por West de un contexto público tradicional con cierto fundamento ritual para el yambo arcaico no es totalmente aceptada (cf. Brown, C. G. Iambos. En: Gerber, D. E. (org.). A Companion to the Greek lyric poets. Leiden: E. J. Brill, 1997, p. 11-88), hoy en día nadie discute el sympósion como principal ocasión para la performance yámbica, cf. Bartol, K. Greek elegy and iambus. Studies in ancient literary sources. Poznan: Uniwersytet im. Adama Mickiewicza w Poznaniu, p. 70, 1993; véase también Rotstein A. The idea of iambos. Oxford: University Press, 2010.

${ }^{5}$ Cf. Leduc C. Sur la "nature véritable" du mythe en Grèce ancienne. Revue de l'histoire des religions. Paris, vol. CCXXI, p. 475-500, 2004, y Calame, C. referential fiction and poetic ritual: towards a pragmatics of myth (Sapho 17 and Bacchylides 13). Trends in Classics. Berlin, vol. I, issue 1, p. 18-35, 2009; estos artículos analizan el rol de la performance poética como acto religioso, particularmente, en relación a la funcionalidad del mito. Sobre el concepto de re-enactment poético en la lírica griega arcaica, véase Nagy, G. Poetry as performance. Homer and beyond. Cambridge: University Press, p. 87-103, 1996, y Nagy, G. Transmission of archaic Greek sympotic songs: from Lesbos to Alexandria. Critical inquiry. Chicago, vol. XXXI, p. 26-48, 2004. 


\section{Estructura de la Inscripción}

En 1949 y 1950, cuatro bloques de mármol fueron descubiertos cerca del valle de Elitas, a tres kilómetros al noreste de Paros, actual Paroikia, Grecia. ${ }^{6}$ Sólo dos de ellos, E1 y E2, contienen propiamente la inscripción. El primero posee tres columnas de escritura. La primera de ellas, E1 I, ilegible, conserva restos de cinco palabras. En la segunda columna, E1 II, compuesta de 57 líneas, encontramos la mayor parte del contenido que se ha preservado. Como se verá, su texto comprende las consultas oraculares que Mnesiepes realizó para el establecimiento del' ApXı $\lambda o ́ x \varepsilon ı 0 v$, el relato de iniciación poética de Arquíloco, y un oráculo délfico antiguo que anunciaba la inmortalidad y la fama del poeta. La tercera columna del primer bloque, E1 III, cuya conservación es fragmentaria, narra los sucesos de la primera performance yámbica de Arquíloco en Paros y la recepción que su poética tuvo por parte de los ciudadanos de la isla. Esta columna finaliza con un oráculo délfico, mediante el cual Apolo comunica a los hombres de Paros que cierto mal que ellos sufrían era producto de las injusticias infringidas al poeta, y que sólo podría subsanarse rindiéndole los honores merecidos. Del segundo bloque de mármol, E2, apenas se ha podido restaurar el contenido en una idea general, en él se narra el valor y el coraje de Arquíloco en distintos sucesos bélicos.

En cuanto a su datación, Kontoleon observó que la pequeña y elegante grafía de la "Inscripción" era similar a la del "Marmor Parium" (264/ 3 a. C.), lo cual nos permite situarlo hacia mediados del s. III a. C. 7

\footnotetext{
${ }^{6}$ En la edición canónica de Kontoleon los cuatro bloques de mármol están enumerados de la siguiente manera: E1, E2, E3 y E4. En los dos primeros, E1 y E2, se halla lo que se ha denominado propiamente la "Inscripción de Mnesiepes". El tercero, E3, consigna en su borde izquierdo los nombres Zósimo, Arquíloco, Skopa, Timarco y Glauco; sin embargo, aunque es indudable que esta piedra formaba parte del santuario, su escritura es tardía y no pertenece a la inscripción original de Mnesiepes. El cuarto bloque, E4, presenta el relieve de un toro o vaca que, se supone, formaba parte de un friso que ilustraba la inscripción. Cf. Kontoleon, $\mathrm{N}$.

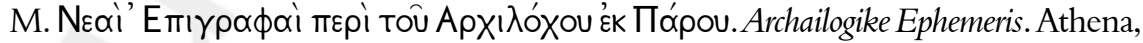
vol. XCI, p. 32-95, 1952, p. 32-95; Kontoleon, N. M., op. cit., 1956a, p. 397-406; Kontoleon, N. M., op. cit., 1956b, p. 29-39; véase también, Clay, op. cit., p. 104-110. Sobre la localización y disposición del recinto sagrado, véase Ohnesorg A. Der dorische Prostylos des Archilocheion auf Paros. Archäologischer Anzieger. Berlin, heft II, p. 271-90, 1982, y Clay, op. cit., p. 35-39.
}

${ }^{7}$ Cf. Kontoleon, op. cit., 1952, p. 36. 
Por otra parte, distintos datos, proporcionados por la inscripción misma o provenientes de otras fuentes, nos permiten inferir que el culto heroico a Arquíloco existía en la isla de Paros desde tiempos antiguos. Al respecto, un testimonio interesante aparece en Retórica:

Y como [dice] Alcidamas, que todos rinden honores a los sabios: "Los de Paros han honrado a Arquíloco a pesar de ser blasfemo; los de Quíos a Homero aunque no poseía cargos públicos; ${ }^{8}$ los de Mitilene a Safo aun siendo mujer; los lacedemonios hicieron a Quilón del consejo de ancianos, por más que ellos no eran aficionados a las letras; los de Italia a Pitágoras, y los de Lampsaco dieron sepultura pública a Anaxágoras, aun siendo extranjero, y le honran incluso hoy; y los atenienses, sirviéndose de las leyes de Solón, fueron felices, y los lacedemonios de las de Licurgo; y en Tebas, cuando los magistrados se hicieron filósofos, también la ciudad fue feliz".

En este pasaje, Aristóteles, al hablar sobre el uso retórico de la

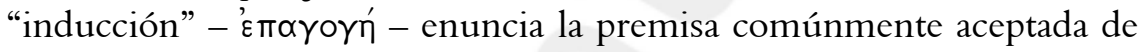
que "todos honran a los sabios". Para argumentar esta premisa cita al retórico Alcidamas (fines del siglo $\mathrm{V}$ y principios del IV a. C), discípulo de Gorgias, el cual nombra a los sabios que recibieron honores en la

${ }^{8}$ Tодıтıкóv "ejercer cargos públicos", seguimos la lectura de Freese J. H. The 'art' of rhetoric. Cambridge /London: Harvard University Press, 1926, vol. XXII, p. 308. Aunque Toגı тıкóv aparece en el "Codex Ac: Parisiensis 1741", la edición canónica

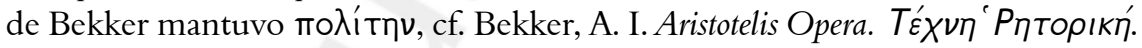
Berlin: Academia Regia Borussica, 1831. T. II, p. 1398. Sin embargo, como sostiene

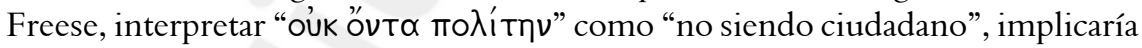
obviar que los habitantes de Quíos reclamaban enfáticamente el reconocimiento de su ciudad como lugar de nacimiento de Homero; cf. Cope E. M. An introduction to Aristotle's rhetoric. With analysis, notes and appendices. Cambridge/London: Macmillan, p. 1867, 261-262.

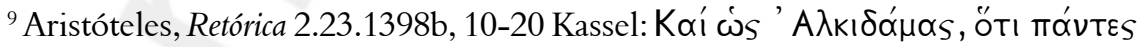

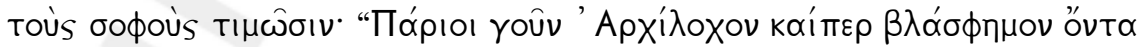

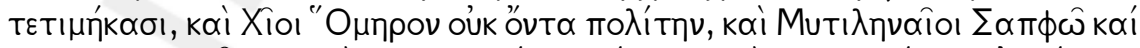

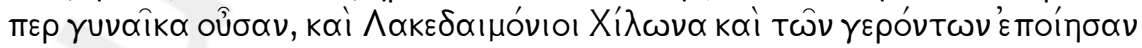
ந̄kı

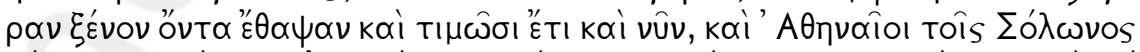

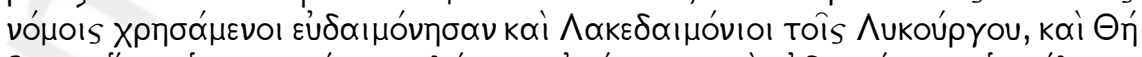

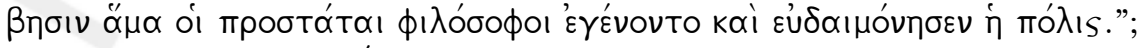
(2.23.1398b, 12 moגıтıкóv Freese). Las traducciones al castellano de los textos griegos son propias. 
Grecia arcaica, entre ellos el poeta Arquíloco a quien los habitantes de Paros tributaron las debidas honras.

\section{Mnesiepes viaja a Delfos}

El texto de la inscripción se inicia con tres respuestas oraculares (E1 II, 1-7, 8-13, 14-15) que Mnesiepes recibió de Apolo para el establecimiento en Paros del santuario consagrado al culto de Arquíloco. ${ }^{10}$ Estos oráculos poseen una estructura formular y contienen disposiciones precisas para la realización de los sacrificios en los altares que ya se han erigido dentro del recinto.

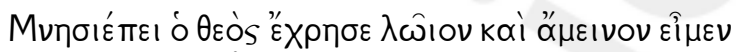

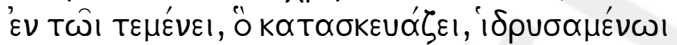

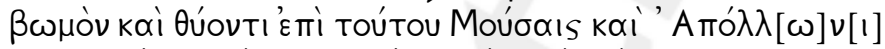

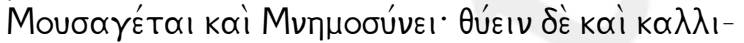

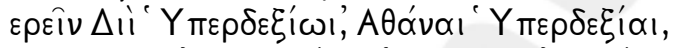

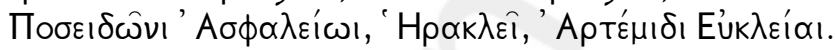

Пu$\theta \omega \hat{\delta \varepsilon} \tau \omega \hat{\imath}$ ' A

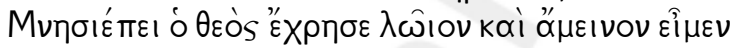

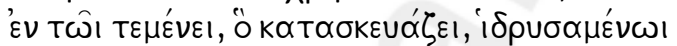

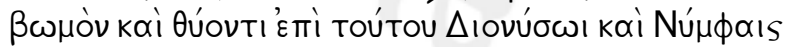

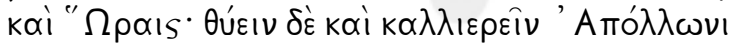

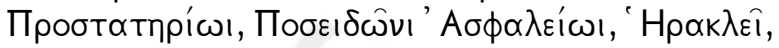

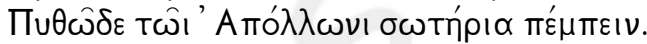

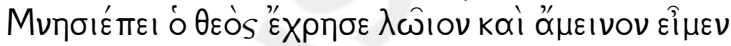

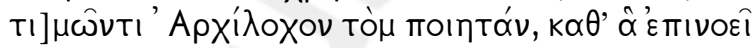

(E1 col. II, 1-15, Clay)

El dios anunció a Mnesiepes lo que era conveniente y apropiado

en el recinto sagrado, que está construyendo, donde ha situado

un altar en que se hacen ofrendas a las Musas, a Apolo

conductor de las Musas y a Mnemósine: ofrecer sacrificios propi-

cios a Zeus supremo, a Atenea suprema,

al seguro Poseidón, a Heracles, a la gloriosa Ártemis.

A Apolo pítico enviar ofrendas de agradecimiento.

El dios anunció a Mnesiepes lo que era conveniente y apropiado

en el recinto sagrado, que está construyendo, donde ha situado

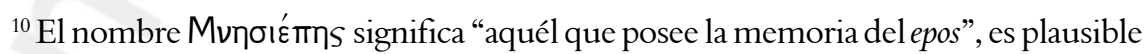
que Mnesiepes fuera un aedo o rapsoda; cf. Nagy, G. The best of the Achaeans. Concepts of hero in archaic Greek poetry. Baltimore: The Johns Hopkins University Press, 1979 (ch. 18.4 n. 3). 
un altar en que se hacen ofrendas a Dioniso, a las Ninfas y a las Horas: ofrecer sacrificios propicios al protector Apolo, al seguro Poseidón, a Heracles.

A Apolo pítico enviar ofrendas de agradecimiento.

El dios anunció a Mnesiepes lo que fuera conveniente y apropiado para honrar al poeta Arquíloco, según lo cual dispone.

De acuerdo con lo que podemos deducir del texto, originariamente Mnesiepes habría dispuesto dos altares sobre los cuales se realizarían sacrificios a tríadas de divinidades íntimamente relacionadas. ${ }^{11} \mathrm{El}$ primero

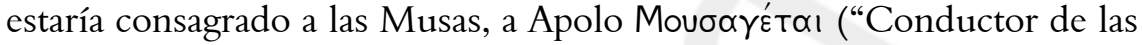
Musas") ${ }^{12}$ y a Mnemósine, madre de ellas. El segundo altar, por su parte, a Dioniso, a las Ninfas, que criaron a Dioniso ocultándolo de Hera por pedido de Zeus, y a las Horas, que suelen acompañar el cortejo del dios. Sin embargo, Apolo - ó Acós- ordena al propio Mnesiepes expandir la tríada originaria de deidades para las ofrendas propiciatorias. Esta disposición tiene como fin incluir el culto de divinidades relacionadas con Paros o con su colonia Tasos. ${ }^{13}$ Como lo dictamina el oráculo, en el primer altar también deberán recibir sacrificios Zeus

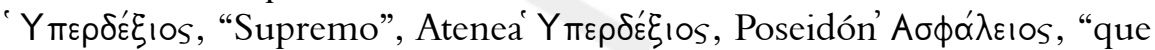
otorga seguridad", Heracles y Ártemis. En el segundo altar, el oráculo dispone que se añadan tributos propiciatorios nuevamente a Poseidón

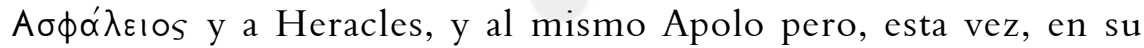
investidura de Пробтати́pios ("Protector"). ${ }^{14}$

${ }^{11} \mathrm{~A}$ los grupos de divinidades que se le tributaban ofrendas en un mismo altar se los

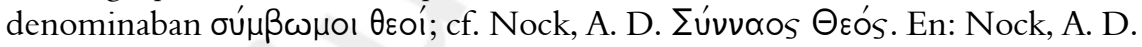
Harvard studies in classical philology. Cambridge, Mass.: Harvard University Press, vol. XLI, p. 1-62, 1930.

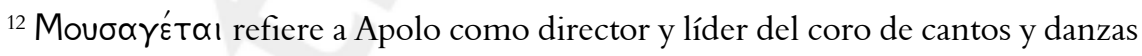
que componen las Musas.

${ }^{13}$ Cf. Aloni A. Poesia e biografia: Archiloco, la colonizzazione e la storia. Annali online di Ferrara. Ferrara, vol. I, p. 64-103, 2009.

${ }^{14}$ El culto que establece Mnesiepes originariamente estaría centrado en las divinidades protectoras de la poesía: Apolo, las Musas y Mnemosine; y en los misterios dionisíacos: Dioniso, las Ninfas y las Horas. Probablemente la disposición de las ofrendas a Zeus Hyperdéxios, Atenea Hyperdexía, Poseidón Aspháleios y Ártemis, se vinculen con la vida cívica de la comunidad y la asamblea. Zeus Hyperdéxios y Atenea Hyperdexía aparecen también, como par, en Tasos y Rodas. Su función dentro de la comunidad de Paros podría compararse con la de Zeus Hellánios y Atenea Hellanía en Esparta, y con la de Zeus Sotér y Atenea Sotér en Atenas; cf. Oliver, J. H. Demokratia, the gods, and the free world. Morals and law in ancient Greece. New York: Arno Press, 1979. 
El tercer oráculo que Mnesiepes recibe en Delfos concierne específicamente a la autorización por parte de Apolo del culto heroico de Arquíloco. El dios acepta sin ningún tipo de reparos las disposiciones rituales propuestas por Mnesiepes. En cierto modo, el oráculo legitima el estatus heroico del poeta permitiendo que se le tributen honores dentro del mismo recinto en que están ubicados los altares. Un elemento digno de destacar, sin embargo, es la diferencia entre los

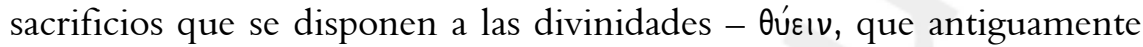
designaba las ofrendas a los dioses realizadas a través de la combustión -, y el término empleado para los honores de Arquíloco - тı $\mu \hat{\alpha} \nu$-, que denota el honrar a alguien sin que conlleve sacrificios propiciatorios. ${ }^{15}$

La serie de oráculos concluye con la realización de las disposiciones

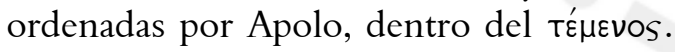

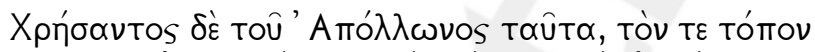

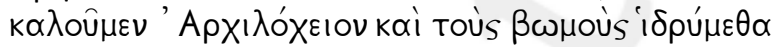

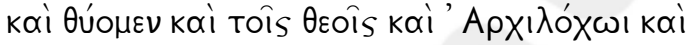

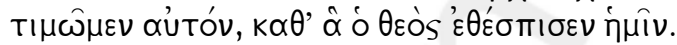

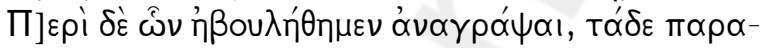

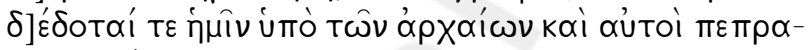

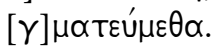

(E1 col. II, 16-22, Clay)

Luego de que Apolo anunciara estas cosas, llamamos

al lugar Arquilóqueion, ${ }^{16}$ hemos dispuesto los altares,

ofrecemos los sacrificios tanto a los dioses como a Arquíloco,

y lo honramos, de acuerdo con lo que el dios nos ha revelado.

Acerca de lo que deseamos conservar por escrito, estas cosas han

sido transmitidas a nosotros por los antiguos y nosotros mismos las

hemos elaborado.

\footnotetext{
${ }^{15}$ El verbo tı $\alpha \hat{\nu} \nu$ es el mismo empleado en la cita de Alcidamas sobre el honor que

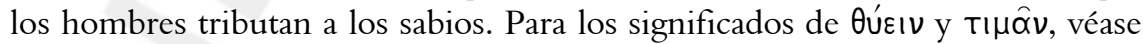
Liddell, H. G.; Scott, R.; Jones, H. S. A Greek-English lexicon. With a revised suplement. Oxford: Clarendon Press, 1996; y Chantraine, P. Dictionnaire étymologique de la langue grecque. Histoire des mots. Paris: Klincksieck, 1980.

${ }^{16}$ Es muy probable que el recinto sagrado-Arquilóqueion -construido por la comunidad de Mnesiepes se encontrara en el mismo lugar en el que estaba la tumba del poeta.

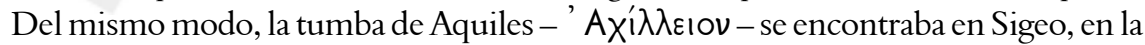
Tróade, junto con las tumbas de Patroclo y Antíloco; cf. Odisea XXIV, 71-84.
} 
Si tenemos en cuenta que los oráculos estaban dirigidos explícitamente a Mnesiepes, es notorio, en esta parte de la inscripción, el desplazamiento hacia la primera persona plural. Este dato nos permitiría postular a Mnesiepes como representante de una comunidad

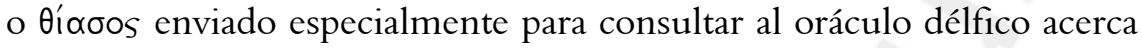
de las honras de Arquíloco en Paros. ${ }^{17}$ Nos encontraríamos, entonces, frente a un grupo de devotos que ha decidido, hacia el siglo III a. C., institucionalizar a través de la construcción de un santuario el culto del poeta. Uno de los propósitos de esta comunidad, como nos indica la

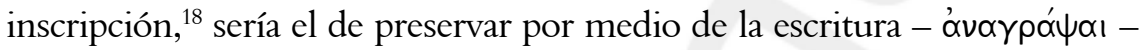
aquellos conocimientos acerca del poeta que heredaron de la antigüedad en forma de tradición oral; pero también, aquellos que los miembros

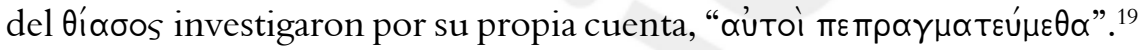
Además de la preservación, la escritura funcionaría como medio de

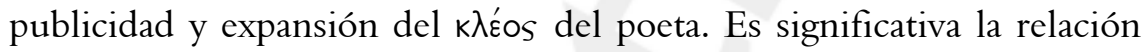
que se establece entre el acto de preservar viejos relatos orales a través

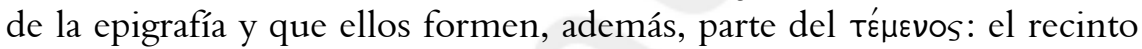
sacro, luego de ser instruido por la divinidad, canonizaría las palabras inscriptas en sus paredes otorgando un estatuto de verdad a los relatos que ellas contienen y, al mismo tiempo, son esas palabras las que narran el devenir del poeta como héroe desde su encuentro con las Musas hasta la aceptación por parte de Apolo de la construcción de esas mismas paredes. Es indudable, sin embargo, que los relatos que contiene la inscripción ya habrían adquirido, por sí mismos, cierta autoridad entre los discursos religiosos de la isla, si no ¿cómo podría comprenderse su preservación oral durante más de dos siglos?

Unas de las tradiciones orales que el bíaoos recoge, como veremos a continuación, es el famoso relato del encuentro entre Arquíloco y las Musas y los acontecimientos de su iniciación poética.

${ }^{17}$ Cf. Tarditi G. La nuova epigrafe archilochea e la tradizione biografica del poeta. Par. del Pass., Napoli, vol. XI, n. 2, p. 139, 1956.

${ }^{18}$ Cf. "Inscripción de Mnesiepes” E1 col. II, 20, Clay.

${ }^{19}$ Cf. "Inscripción de Mnesiepes” E1 col. II, 21-22, Clay. 


\section{Arquíloco dirige palabras obscenas a las Musas}

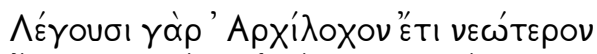

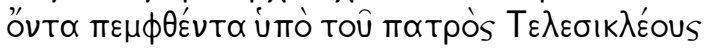

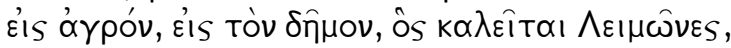

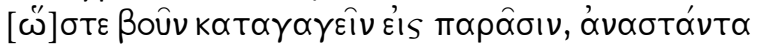

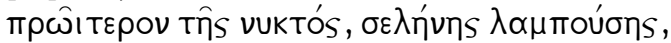

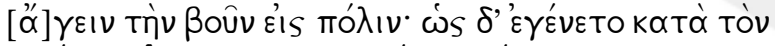

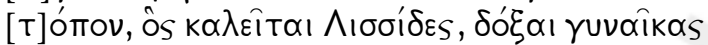

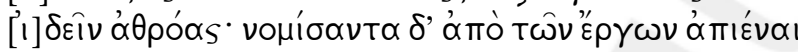

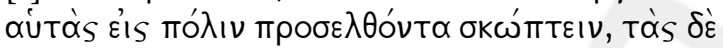

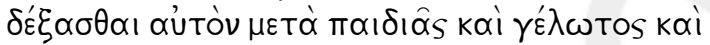

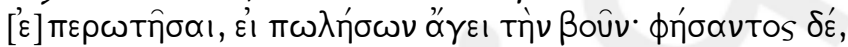

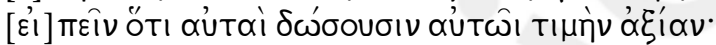

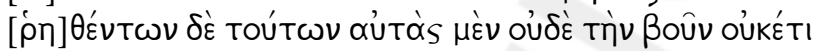

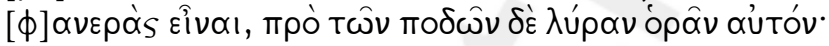

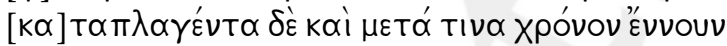

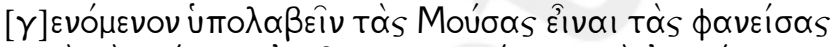

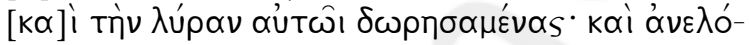

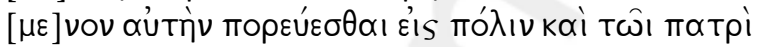

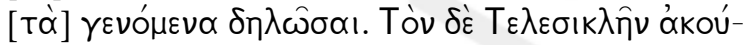

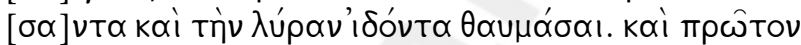

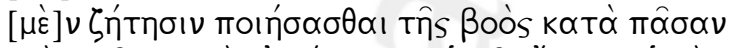

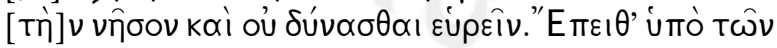

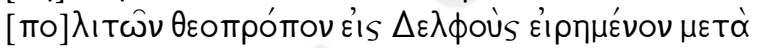

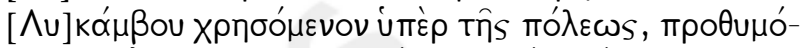

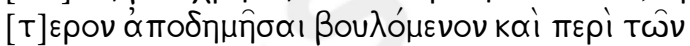

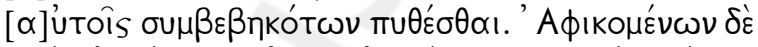

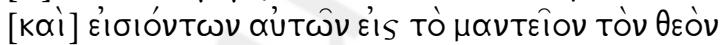

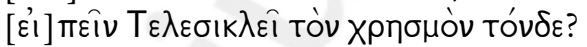

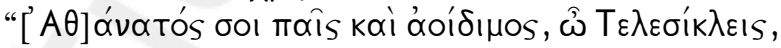

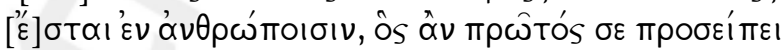

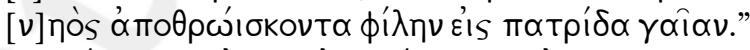

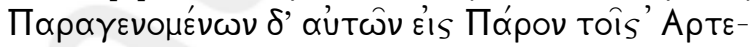

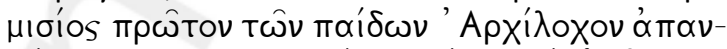

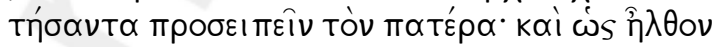

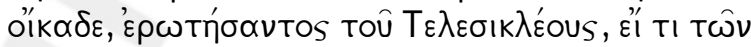

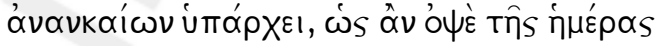

(E1 col. II, 22-55, Clay)

Dicen que Arquíloco, todavía joven,

habiendo sido enviado por su padre Telesicles

al campo, al distrito que se llama Prados,

con el fin de traer una vaca para la venta, se levantó 
aún de noche, cuando la luna brillaba, y condujo la vaca a la ciudad. Cuando llegó al lugar, que se llama Piedras Lisas, le pareció ver a unas mujeres reunidas. Y como consideró que regresaban de las labores a la ciudad, acercándose a ellas les hizo bromas obscenas, y ellas lo aceptaron con diversión y risas, y como le preguntaron si llevaba la vaca para vender, habiendo respondido que sí, ellas le dijeron que le darían un justo precio; pero, una vez dicho esto, ni ellas ni la vaca eran ya visibles, y él vio una lira a sus pies.

Estupefacto, después de cierto tiempo, y tras recuperar la conciencia, comprendió que las Musas eran quienes habían aparecido y le habían obsequiado la lira. Después de tomarla se dirigió a la ciudad y manifestó a su padre lo sucedido [...] Telesicles, al escucharlo y ver la lira, se sorprendió. Primero realizó una búsqueda de la vaca por toda la isla y no pudo hallarla[...] Luego, designado por los ciudadanos emisario a Delfos, junto con Licambes, para consultar acerca de la ciudad, se mostró predispuesto de partir porque deseaba preguntar también acerca de lo que les había sucedido a ellos [...] Después de arribar e ingresar en el recinto profético, el dios dijo a Telesicles este oráculo:

"Tendrás un hijo inmortal y celebrado, Telesicles, entre los hombres, el que primero te salude cuando bajes de la nave a la amada tierra patria".

Luego de que ellos regresaran a Paros, durante las Artemisas, Arquíloco fue el primer hijo en salir al encuentro para saludar a su padre. Cuando regresaban

a casa, Telesicles le preguntó si algo de lo necesario estaba disponible, ya que era tarde en el día

Como se puede apreciar, el verbo $\lambda \dot{\varepsilon} \gamma$ ovol, que introduce en discurso indirecto el encuentro de Arquíloco con las Musas, nos indica que en la isla existía al menos un relato de su iniciación poética. Si bien, la tradición oral recordada por Mnesiepes tiene las características de un cuento folclórico, ${ }^{20}$ es necesario destacar que también mantiene una relación directa con la tradición poética vinculada indisolublemente con la esfera religiosa. Por un lado, las bromas obscenas que Arquíloco dirige

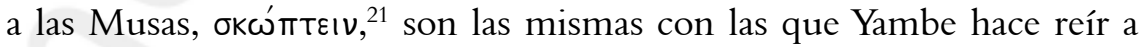

${ }^{20}$ Cf. Clay, op. cit., p. 14.

${ }^{21}$ Cf. "Inscripción de Mnesiepes” E1 col. II, 30, Clay. 


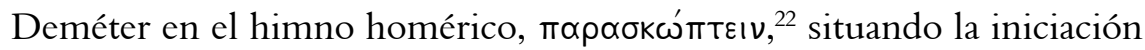
dentro del marco de la áıxpoגoría del ritual eleusino. Por otro lado, el suceso de la teofanía nos ubica dentro del paradigma de la iniciación poética en Grecia. La escena del encuentro entre el poeta y las Musas constituye un patrón narrativo tradicional con elementos en cierta medida convencionales. ${ }^{23}$ Sin lugar a dudas, el relato más representativo de este tópico y, al mismo tiempo, más cercano al de Arquíloco es la epifanía de las Musas en el monte Helicón, narrada por el propio Hesíodo. ${ }^{24} \mathrm{~A}$ los fines de nuestro análisis nos parece importante destacar las siguientes correspondencias:

1) El encuentro con las Musas sucede en un sitio distante $y$ solitario. En Teogonía, el hecho ocurre en el monte Helicón, morada de las Musas; en la "Inscripción de Mnesiepes", en un paraje que se denomina "Piedras Lisas" - $\Lambda ı \sigma \sigma i \delta \varepsilon S-.{ }^{25}$

2) La epifanía sucede mientras las Musas están deambulando

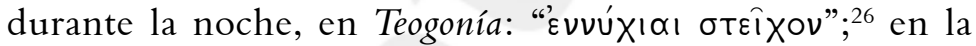

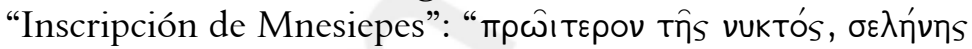
$\lambda \propto \mu \pi$ тúons". ${ }^{27}$

3) Es un pastor a quien las Musas se le aparecen: Hesíodo cuida las ovejas en el monte Helicón; Arquíloco, aunque circunstancialmente, conduce una vaca para su venta.

\footnotetext{
${ }^{22}$ Himno Homérico a Deméter, 200-204; el pasaje en cuestión describe el arribo de Deméter a la casa de Celeo en Eleusis. Sumida en una profunda aflicción a causa del rapto de su hija Perséfone, Deméter rechaza sentarse, hablar, comer y beber, hasta

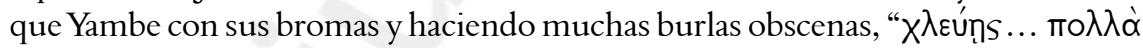

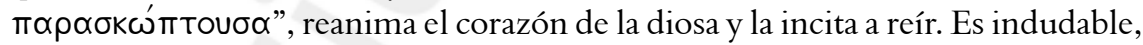
por otro lado, que los términos ' lá $\mu \beta \eta$ y 'i $\alpha \mu \beta o s$ están etimológicamente relacionados; cf. Rotstein, op. cit., p. 167-182.

${ }^{23}$ Cf. West M. L. Hesiod. Theogony. Oxford: University Press, 1966, p. 158-161; partiendo de la iniciación poética de Hesíodo, la compara con epifanías divinas de poetas y profetas en las tradiciones griegas y hebreas; véase también Calame, C. The craft of poetic speech in ancient Greece. Traducción bajo la dirección de Janice Orion. New York: Cornell University Press, 1995, p. 58-74, y el análisis del tópico en Grecia y Roma realizado por Williams, F. Archilochus and the eunuch: the persistence of a narrative pattern. Classics Ireland. Dublin, vol. I, p. 96-112, 1994.

${ }^{24}$ Hesíodo, Teogonía 1-36.

${ }^{25}$ Cf. "Inscripción de Mnesiepes" E1 col. II, 28, Clay.

${ }^{26}$ Hesíodo, Teogonía 10.

${ }^{27}$ Cf. "Inscripción de Mnesiepes" E1 col. II, 26, Clay.
} 
4) Las Musas conceden el don de la palabra poética junto con un elemento visible que funciona como símbolo de autoridad: Hesíodo recibe como cetro una rama de laurel "ó $\zeta o s$

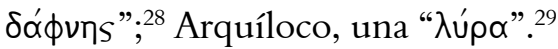

A diferencia de la iniciación poética de Hesíodo, es notorio que sea Arquíloco quien tome la iniciativa al burlarse de las Musas, las cuales

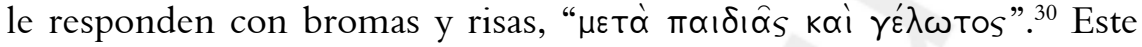
intercambio verbal y gestual entre el poeta y las Musas podría pensarse como presagio del carácter jocoso y de la incitación a la risa que posee la poética de Arquíloco. Por el contrario, en Teogonía las Musas se dirigen al poeta en tono imprecatorio: "pastores rústicos, vil oprobio, vientres solamente", ${ }^{31}$ y la narración del encuentro adquiere una atmósfera mucho más sublime, concordando con la impronta de la obra.

Ambos relatos manifiestan ciertos pactos que se sellan con el $\delta \omega \hat{p o v}$ que las Musas otorgan al poeta. Este don, que como hemos dicho simboliza la autoridad proveniente de la divinidad, implica la competencia en un campo poético determinado. Es decir, en Hesíodo

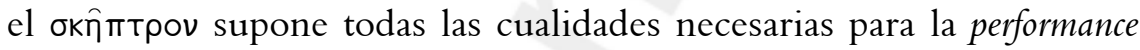
rapsódica cuyo compás es marcado con el golpe del póßjos; podríamos incluir, también, las $\alpha \lambda \eta \eta \varepsilon^{\prime} \alpha$ que las Musas infunden a Hesíodo, diferenciando sus palabras de las $\psi \varepsilon u ́ \delta \varepsilon \alpha$ inspiradas a otros poetas dentro, seguramente, de un contexto de concurso rapsódico. ${ }^{32}$ En el caso de Arquíloco, la $\lambda u ́ p \alpha$ sintetiza el saber de la performance poética acompañada por ese instrumento. ${ }^{33}$ Consecuentemente con el otorgamiento del don,

${ }^{28}$ Hesíodo, Teogonía 30.

${ }^{29}$ Cf. "Inscripción de Mnesiepes" E1 col. II, 35, Clay.

${ }^{30}$ Cf. "Inscripción de Mnesiepes” E1 col. II, 31, Clay.

${ }^{31}$ Hesíodo, Teogonía 26ss.

${ }^{32}$ Hesíodo, Teogonía 26-28.

${ }^{33}$ El otorgamiento de la lira es problemático en relación al tipo de poesía que Arquíloco compone. Si consideramos que la elegía y el yambo estaban acompañados exclusivamente del aulos, estaríamos aquí ante una contradicción. Sin embargo, Iannucci y Aloni declaran en el apéndice de su libro, dedicado a la nueva elegía de Arquíloco, que el poeta de Paros practicó otros géneros poéticos, propiamente líricos, cf. Aloni, A.; Iannucci, A. L'elegia greca el'epigrama dalle origini al V secolo. Con un'appendice sulla "nuova" elegia di Archilocho. Firenze: Le Monnier, 2007, p. 101-107. Por otro lado, en los ff. 63 y 120 Tarditi, Arquíloco nombra la lira y menciona el acompañamiento del aulos y la lira, respectivamente. 
el poeta se constituye como siervo, $\theta \varepsilon \rho \alpha \dot{\pi} \pi \omega \nu,{ }^{34}$ de las Musas. En Teogonía,

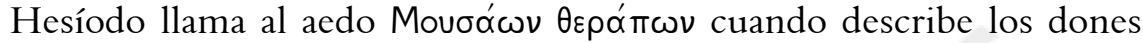
que ellas otorgan tanto al poeta como al rey. ${ }^{35}$ En forma similar, Arquíloco

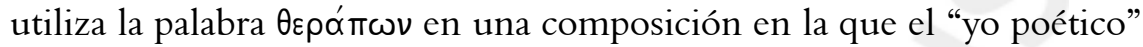
define su singularidad: "Yo soy siervo del soberano Enialio y conocedor del amado don de las Musas". ${ }^{36}$

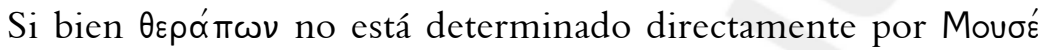
$\omega o v$ sino por 'Evva $\lambda$ íoro, en el contexto en que Arquíloco lo enuncia manifiesta un vínculo solidario con el ámbito de ambas potencias, ya que sintetiza dos vertientes de una misma individualidad, las dos funciones o roles que el "yo" asume dentro de su comunidad: soldado y poeta. Además de la referencia que encontramos en su propia obra, existen otros testimonios que designan al héroe de Paros como siervo de las Musas. La "Inscripción de Sóstenes", que toma el nombre del historiador y biógrafo de Paros del siglo I a. C., concluye la biografía de Arquíloco con un epigrama en forma de diálogo entre un peregrino que pasa frente a la tumba del poeta y este último que yace allí sepultado:

(Peregrino)
¿Quién te cinceló en la piedra como el siervo de las Musas,
joven hijo de Telesicles, glorificándote?

(Arquíloco)

Te diré ciertamente la verdad, si no la sabes:

un noble, no carente de virtud,

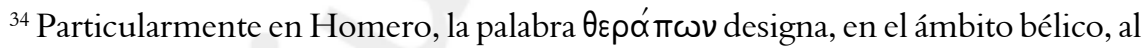
escudero o a quien conduce el carro del héroe épico; en este contexto, adquiere una carga semántica de lealtad y coraje en función de la defensa del héroe, ratificada

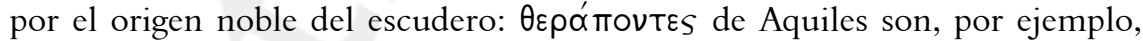
Patroclo, Automedonte y Álcimo (Ilíada, V.580; VIII.119; XXIV.474). En un ámbito más doméstico, aunque no necesariamente, implica una relación de subordinación y servidumbre: servidor, siervo, criado (Od., XVI.253). Específicamente, en el plano divino, denota un vínculo de devoción religiosa: devoto, adorador, creyente; a los guerreros importantes se los denomina $\theta \varepsilon \rho \alpha ́$ птоvтєs de Ares (Od., XI.255; Il., II.110). En la poesía posterior se utiliza la expresión "servidor de las Musas" para designar al poeta o al aedo, en el mismo nivel de tékhne en que un carpintero sirve a Atenea

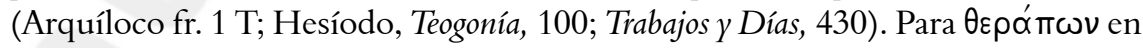
relación con Arquíloco véase Nagy, G., op. cit., 1979 (ch. 12).

${ }^{35}$ Hesíodo, Teogonía 99-100.

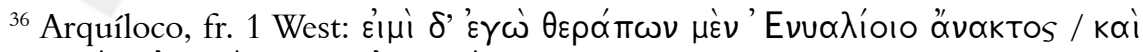

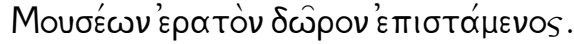


Sóstenes, hijo de Próstenes, de mi canto de muchos temas extrajo una parte de los honores que fluyen constantemente. ${ }^{37}$

Aunque el testimonio es tardío, nos permite inferir que luego de la muerte de Arquíloco, momento en que comienza a gestarse el relato

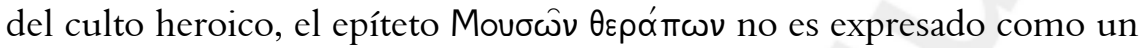
simple elogio hacia el poeta, sino que constituye un atributo de su individualidad en tanto su función dentro de la comunidad ha sido canonizada por Apolo y las Musas. ${ }^{38}$ En relación a su faz bélica y a su propia muerte, la tradición refiere que Arquíloco fue asesinado en el campo de batalla, sirviendo al dios Ares, ${ }^{39}$ por un mercenario de Naxos llamado Calondas. En búsqueda de purificación por esta muerte, Calondas se dirigió al santuario de Delfos donde su entrada fue rechazada a través del siguiente oráculo: "Al siervo de las Musas asesinaste; ivete del templo!" 40

${ }^{37}$ Cf. "Inscripción de Sóstenes" B VII, 12-17, Chaniotis (=Archilocho T 5, Tarditi):

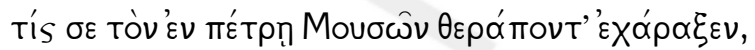

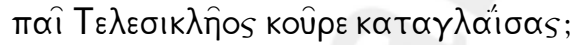

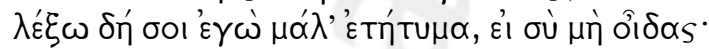

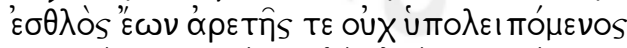

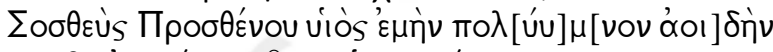

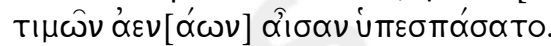

${ }^{38}$ En este punto disentimos de la interpretación que Clay realiza sobre la "Inscripción de Sóstenes". Para él: Sosthenes' description of Archilochos as the 'servant of the Muses' invites attention. Evidently, Sosthenes was not an attentive reader of Archilochos fr. 1 West, for he refers to him not as the servant of Lord Enyalios, but the servant of the Muses; cf. Clay, op. cit., p. 34; es muy probable que Sóstenes, nativo de Paros y biógrafo de Arquíloco, haya realizado una correcta lectura de la composición citada, y es muy probable, también, que estuviera pensando en Teogonía 100, de donde Clay considera que

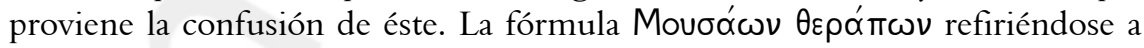
Arquíloco, como veremos, aparece también en el oráculo dirigido a Calondas, aquél que dio muerte al poeta. Seguramente Sóstenes conoció este oráculo ya que aparece en varias fuentes antiguas; esto nos permitiría suponer una lectura y una interpretación más sutil del fragmento por parte del biógrafo.

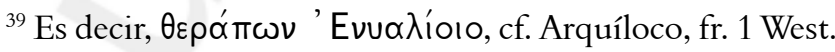

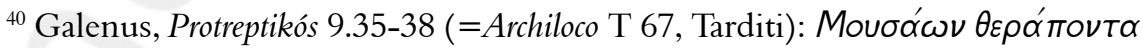

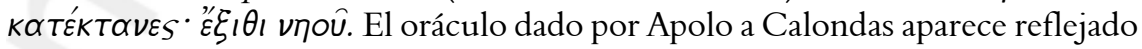
en varias fuentes antiguas, tomamos para su referencia: Galenus, Protreptikós 9.35-38 (=Archiloco T 67, Tarditi) para el texto del oráculo, y Suda A 4112 (=Archiloco T 170, Tarditi) para su contextualización. 


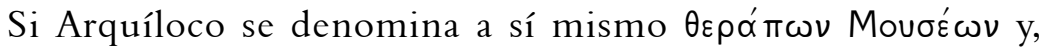
posteriormente, la tradición, como en el caso de Sóstenes, reconoce la validez de este epíteto, sólo es posible porque Apolo en su carácter de

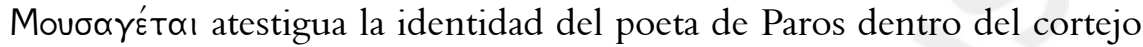
que componen las Musas. A través de los distintos oráculos délficos que constituyen la historia del culto heroico de Arquíloco, la intervención de la palabra religiosa tutelada por Apolo legitima el carácter ritual de la persona y de su poética. Es interesante recordar, haciendo una enumeración de las distintas intervenciones de este dios, que el entramado oracular comienza a tejerse siendo Arquíloco bastante joven, con el anuncio a Telesicles de la predestinación de su hijo; un segundo punto, como veremos ${ }^{41}$ lo conforma la consulta realizada por los habitantes de Paros con posterioridad a la primera performance de Arquíloco; en tercera instancia, Apolo manifiesta su favor hacia el héroe

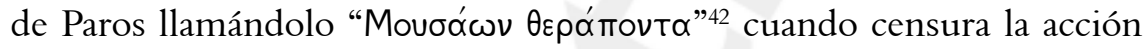
de Calondas; por último, algunos siglos después, la trama profética concluye con las instrucciones que Mnesiepes recibe en Delfos para la disposición de los ritos cultuales en honor del héroe. Es decir, Apolo interviene en cada una de las etapas que constituyen el culto heroico, desde el anuncio de un destino decidido por las potencias divinas hasta la instalación del recinto sagrado, punto culminante de la apología. Evidentemente, el arco temporal entre estas dos instancias oraculares trasciende toda previsión humana. Podríamos suponer que en el momento en que Apolo se dirige a Telesicles presagia, al mismo tiempo, la construcción del santuario. El cumplimiento de la profecía hace que la temporalidad mítica se inserte en una temporalidad histórica avalando la veracidad del relato heroico. Consideramos, por lo tanto, que el relato de iniciación y la palabra oracular urden el tejido religioso que legitima la poética de Arquíloco dentro de los diversos discursos culturales que rigen la comunidad de la isla de Paros.

En resumen, el relato de iniciación manifiesta que el don otorgado por la divinidad exige la devoción y fidelidad por parte del poeta, $\theta \varepsilon \rho \alpha ́ \pi \omega \nu$.

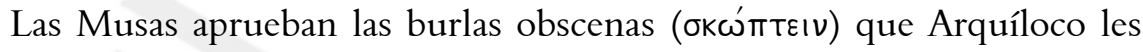
dirige, al iniciarlo en la poesía yámbica. Y, en última instancia, es el oráculo de Apolo el que garantiza la autoridad del poeta en el ámbito de la palabra poético-religiosa. Por lo tanto, si el relato de la tradición permite conocer cómo se desarrollaron los sucesos de la teofanía y de

\footnotetext{
${ }^{41}$ Ver apartado 5.

${ }^{42}$ Galenus Protreptikós 9.38.
} 
la iniciación poética de Arquíloco, el oráculo dispone el destino del poeta dentro del cortejo de las Musas que encabeza el propio Apolo.

\section{Primera performance pública de Arquíloco}

Aunque el resto de la inscripción, que pertenece ya a la tercera columna del primer bloque, no permite una lectura continua debido a que los márgenes superior y derecho de este mármol se encuentran muy deteriorados, sí se ha podido reconstruir una idea general de su contenido.

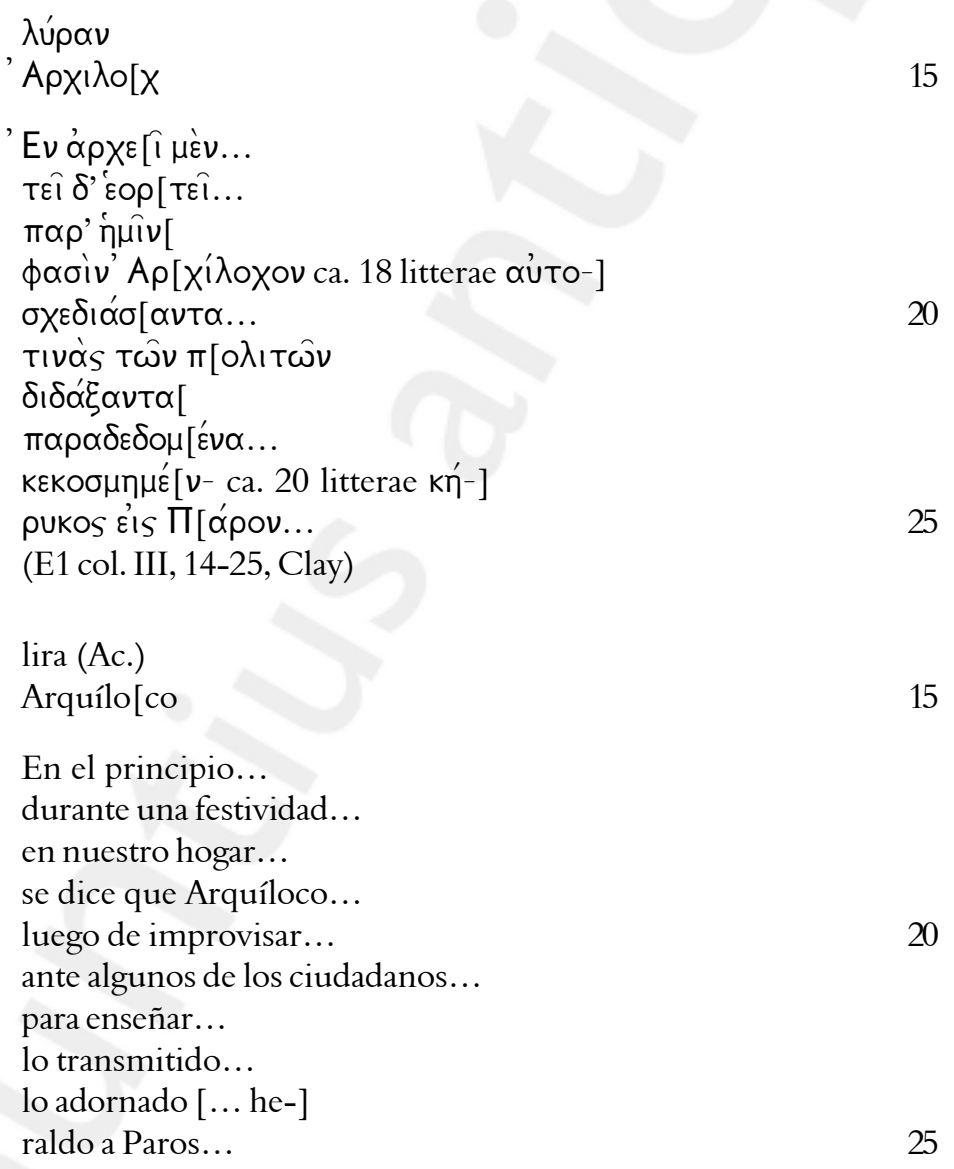

Como se puede apreciar, el estado de la inscripción es muy fragmentario por ende sus interpretaciones dejan lugar a controversias. Prácticamente, las primeras 15 líneas que inician esta columna se han 
perdido, sólo las palabras "lira" (1. 14) y "Arquíloco" (1. 15) aparecen como indudables. En la línea 16, un parágrafo nos anuncia el pasaje hacia una nueva temática. El texto continúa la narración de los hechos sucedidos con posterioridad al regreso de Telesicles. Podemos inferir, por lo tanto, que la festividad a la cual se refiere en la 1.17 son las propias Artemisas citadas en la columna anterior. ${ }^{43}$ El verbo фaoív nos anuncia que Mnesiepes, nuevamente, va a introducir un relato preservado por la tradición oral de la isla. El episodio que narra este relato se relaciona con la primer performance poética de Arquíloco en Paros. ${ }^{44}$ Probablemente, las líneas 16-25 ofrecían el contexto de la presentación pública del poeta y la atmósfera de su recepción; es decir, Arquíloco en una ocasión ritual improvisando una composición frente a un grupo de ciudadanos de la isla. Mnesiepes cita la parte inicial de esta improvisación; lamentablemente, se han preservado sólo las primeras palabras de cada línea. ${ }^{45}$

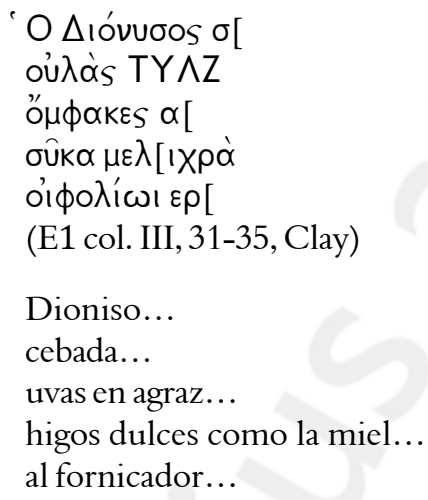

${ }^{43}$ Cf. “Inscripción de Mnesiepes” E1 II, 54.

${ }^{44}$ En verdad, no existe ningún motivo para suponer que ésta fue la primer performance de Arquíloco. La arbitrariedad de nuestra concatenación comienza a gestarse al dar por sentado que las festividades a las que refiere la inscripción son las Artemisas nombradas en la columna anterior, instaurando, de este modo, una sucesión temporal inmediata entre la llegada de Telesicles a la isla y la presentación pública de Arquíloco. Sin embargo, dada la fragmentariedad del texto y teniendo en cuenta la relevancia que adquiere este episodio en el relato, nos permitimos la licencia de considerarla como la primer performance de Arquíloco, si no temporal al menos sí en cuanto a su importancia.

${ }^{45}$ Arquíloco, fr. 251 West. 
Se trataría de un himno clético perteneciente al culto de Dioniso

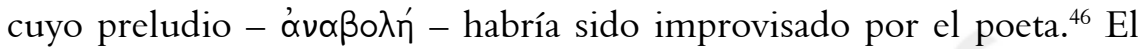
nominativo - 'O $\Delta$ ıóvvбos - permite interpretar el resto del fragmento dentro del campo semántico ligado a los ritos dionisíacos. En este sentido, por ejemplo, los granos de cebada - où $\alpha$ í - eran arrojados sobre las cabezas de los animales que iban a ser sacrificados en distintas

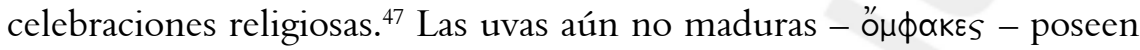
una doble connotación: la primera, refiere en forma literal al fruto característico del culto de Dioniso; la segunda, bajo una acepción metafórica remite a la dureza de los pezones de las jóvenes púberes. La interpretación erótica aparece también en un fragmento alegórico de Alceo que entrelaza la temática agraria y la sexual, allí el "yo poético" figura el acercamiento al cuerpo de una mujer como si se tratase del

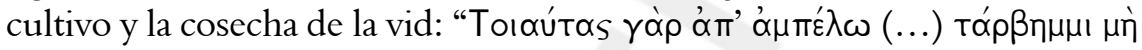

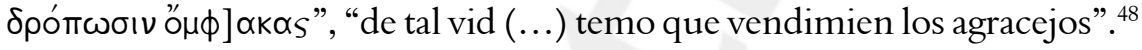

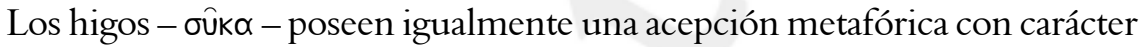
marcadamente sexual. ${ }^{49}$ En Paz de Aristófanes, donde el acto sexual se plasma a través de la imagen de la recolección de granos o frutos -

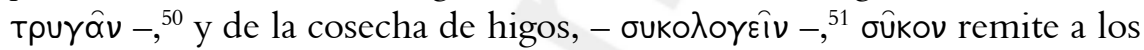

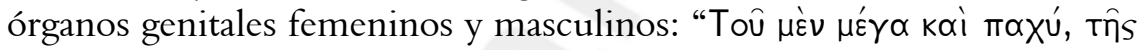

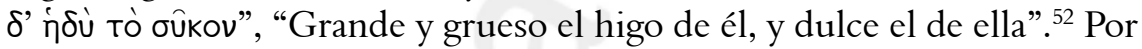

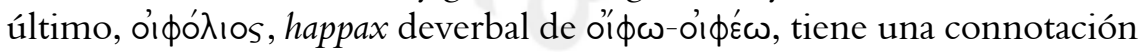

${ }^{46}$ Este preludio, que admite la improvisación, sirve como presentación del canto coral e incluye una dedicatoria a Dioniso; cf. Arquíloco, fr. 120 West. Luego, continuaría el ditirambo interpretado por el coro con motivos estrictamente dionisíacos y tradicionales.

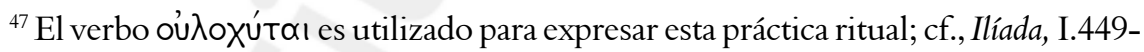
459; Odisea, III.441-42; también, Chantraine, op. cit., 1980, p. 836. Los granos de cebada eran importantes en el culto eleusino, seguramente también en todo rito agrario o de fertilidad, de aquí el epítetó lou $\lambda \omega$ ' atribuido a Deméter; cf. Ateneo, Deipnosophistae 14.10,10-15.

${ }^{48}$ Alceo, fr. 119 Vöigt.

${ }^{49}$ Cf. fr. 331 West (de atribución errónea a Arquíloco): ఠukñ, "higuera”, con sentido obsceno.

${ }^{50}$ Aristófanes, Paz 1339-40.

${ }^{51}$ Aristófanes, Paz 1348.

${ }^{52}$ Aristófanes, Paz 1352-52; cf. también Hiponacte fr.123 Degani, en donde 'ıxás, "higo seco", tiene una clara connotación sexual. Véase Henderson, J. The Maculate Muse. Obscene Language in Attic Comedy. New Haven: Yale University Press, 1975, p. 120-122. 
más vulgar que la propuesta en nuestra traducción, "fornicador". ${ }^{33}$ De cualquier modo, remite a la conducta libidinosa y promiscua de hombres

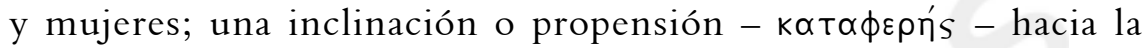
satisfacción del deseo sexual, como lo atestiguan las entradas

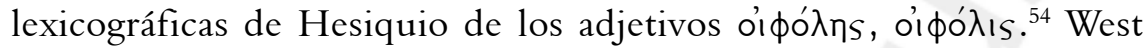
considera, en relación a este fragmento, que óiфódıs es probablemente un epíteto de Dioniso. ${ }^{55}$

El culto dionisíaco parece imbricarse en la poética de Arquíloco. Ateneo, al hablar de los banquetes y la música, cita al ateniense Filócoro (s. III a. C.) quien sostenía "que los antiguos no siempre entonaban ditirambos en las libaciones, sino cuando celebraban a Dioniso con vino y borracheras, ya que a Apolo se lo celebra con tranquilidad y orden"; 56 luego pone como ejemplo una composición de Arquíloco: "Sé cómo iniciar el bello canto del soberano Dioniso,/ el ditirambo, cuando mi corazón ha sido fulminado por el vino". ${ }^{57}$

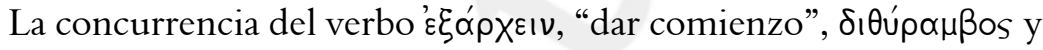
$\Delta ı \omega ́ v$ vos, nos remite inmediatamente al preludio que improvisó el poeta antes de dar paso al canto coral. ${ }^{58}$ Sabemos que los versos de Arquíloco que abren el ditirambo provocaron una reacción adversa por parte del auditorio; por lo que podemos deducir del resto de la inscripción, no parece que los asistentes hayan meramente reprobado la presentación pública, sino que la performance generó un escándalo que terminó en un juicio y, posiblemente, con una sentencia de exilio contra el poeta.

${ }^{53}$ En español rioplatense vulgar podría traducirse como "el cogedor" y en español peninsular "el follador"; cf. Real Academia Española. Diccionario de la lengua española. 22 ed.: "coger", 2001. Disponible en: < http://buscon.rae.es/draeI/> . Consultado el 8 de Junio de 2011.

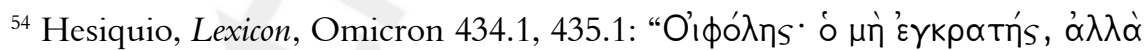

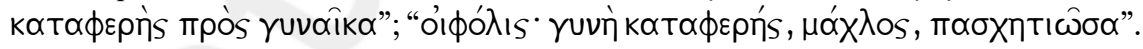
Véase también Lehnus, L. OIФO $\wedge \mathrm{I \Sigma}$. Alla ricerca della fonte di una glossa. Scripta Philologa, Milano, vol. II, p. 159-174, 1980.

${ }^{55}$ Cf. West, op. cit., 1974, p. 25.

${ }^{56}$ Ateneo, Deipnosophistae 14.24, 24-38.

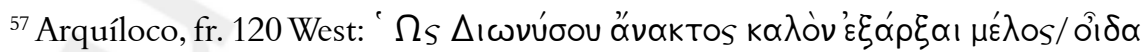

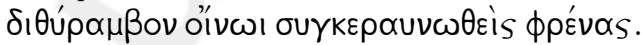

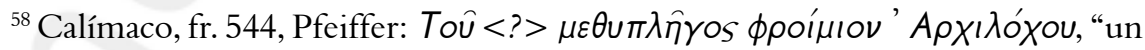
proemio de Arquíloco, golpeado por el vino". Es evidente que Calímaco, contemporáneo de Mnesiepes, tenía conocimiento de la composición que cita

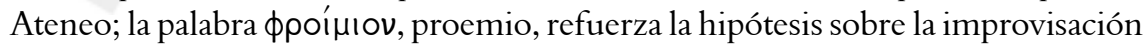
de la ơv $\sim \beta \circ \lambda \eta ́$ que da comienzo al ditirambo; cf. supra nota 46. 


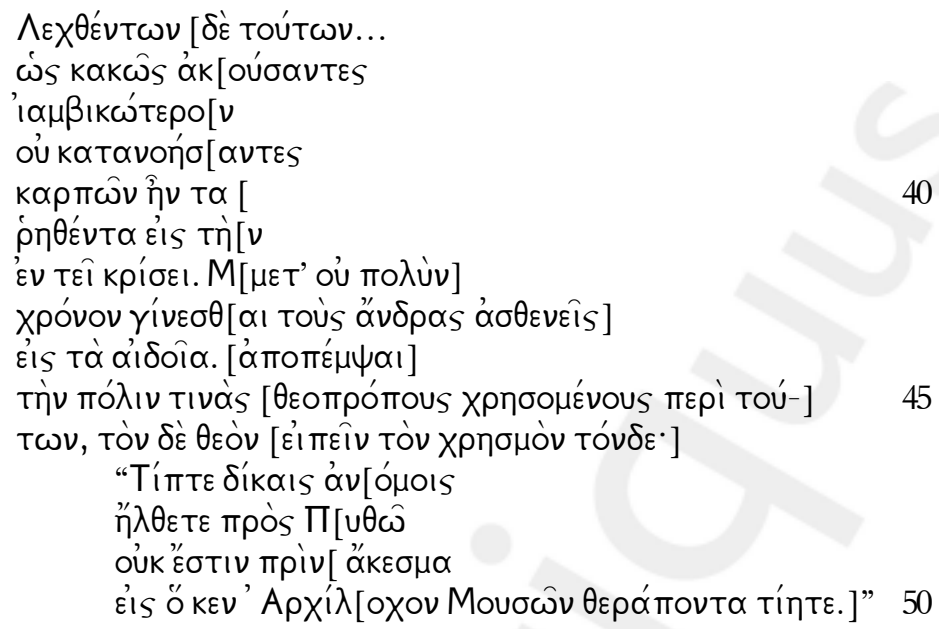

(E1 col. III, 36-46, Clay)

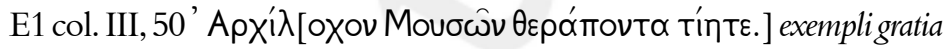
Parke 1958: 93.

después de haber dicho [estas cosas...

como ellos habían oído con mala predisposición...

demasiado yámbico...

no habían comprendido...

eran de frutos...

habiendo sido dirigido a...

en el juicio [no mucho después]

pasó un tiempo [los hombres débiles]

a los genitales. [enviar]

la ciudad algunos [emisarios para consultar sobre estas]

45

cosas, el dios [dijo este vaticinio:]

"¿Por qué por juicios injustos

arribáis a Pytho?

no hay cura hasta que

a Arquíloco, servidor de las Musas, honréis".

Si la integración de Kontoleon a la línea 37 es correcta, k $\alpha \kappa \omega \hat{s}$

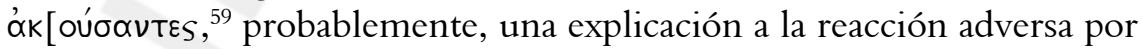

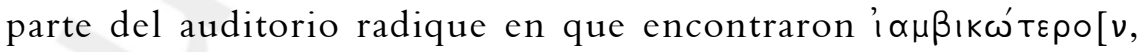
"demasiado yámbica", ${ }^{0}$ la improvisación de Arquíloco. Ahora, ¿qué es lo que implica este exceso de lo yámbico?; si tenemos en cuenta el

${ }^{59}$ Cf. Kontoleon, op. cit., 1952, p. 32-95.

${ }^{60}$ Cf. “Inscripción de Mnesiepes” E1 col. III, 38, Clay. 
análisis realizado de los restos de la composición, ${ }^{61}$ podemos inferir, en cierto modo, que los versos tenían un claro contenido obsceno connotado metafóricamente. Sin embargo, ¿podemos afirmar que ésta fue la razón por la cual los habitantes de Paros rechazaron la poética de Arquíloco hasta el punto de realizar un juicio en su contra? No parece convincente que la obscenidad por sí misma, de carácter ritual o no, por más explícita o velada que haya sido su manifestación, desencadenara una intolerancia de tal magnitud.

La interpretación del escándalo a causa de la obscenidad se relaciona con la hipótesis de la introducción por parte de Arquíloco del culto de Dionisos en la isla, y, con éste, de una nueva forma poética "demasiado yámbica". ${ }^{62}$ Esta perspectiva centra sus argumentos en la tradición que vincula a la familia de Arquíloco con la inserción del culto de Deméter en Tasos durante la colonización llevada adelante por Paros. ${ }^{63}$ Pausanias, en su presentación del famoso pintor Polygnotos de Tasos, nos cuenta que el artista representó en los muros de la Lesche de los Cnidios, en Delfos, una imagen de la barca de Caronte en la cual aparecían las figuras de dos personas jóvenes identificadas como Tellis y Cleóbula. Pausanias señala que Tellis era el abuelo de Arquíloco, padre de Telesicles; y Cleóbula, la mujer que lo acompaña, sería quien habría

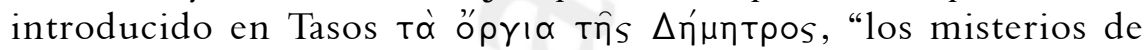
Deméter". ${ }^{64}$ Por otro lado, Tellis y Telesicles son nombres parlantes que se asocian con funciones religiosas del ritual eleusino: $\tau \varepsilon \lambda \varepsilon т \eta \dot{~ r e m i t e ~}$ a la iniciación en los misterios, mientras que $\tau \varepsilon \lambda \varepsilon \sigma \tau \eta \dot{s}$ refiere tanto al que es iniciado como a aquél que inicia a otros en los misterios. ${ }^{65}$ Por último, un argumento a favor de la interpretación de un Arquíloco introductor de los rituales dionisíacos surge en la propia "Inscripción de Mnesiepes", debemos recordar que el consagrado al poeta dedicaba un altar exclusivo para el culto de Dioniso. ${ }^{66}$

\footnotetext{
${ }^{61}$ Cf. "Inscripción de Mnesiepes” E1 col. III, 31-35, Clay.

${ }^{62}$ Cf. Clay, op. cit., p. 19.

${ }^{63}$ Cf. West, op. cit., 1974, p. 27; Gerber, D. E. Greek iambic poetry. From the seventh to the fifth centuries BC. Cambridge, Mass./London: Harvard University Press, 1999; O’Higgins, L. Women and humor in Classical Greece. Cambridge: University Press, 2003, p. 61.

${ }^{64}$ Pausanias, X25-31.

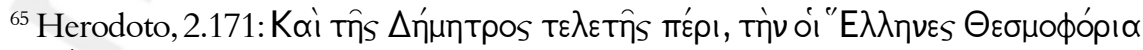

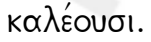

${ }^{66}$ Cf. "Inscripción de Mnesiepes” E1 col. II, 8-13, Clay; también, cf. supra nota 14.
} 
Sin embargo, algunos investigadores consideran que esta interpretación es excesiva y difícil de probar. Para ellos el escándalo de la performance de Arquíloco y, sobre todo, el juicio iniciado en su contra indican que su poética habría encontrado una hostilidad política antes que moral o religiosa. ${ }^{67}$ No sería, por ende, el contenido obsceno de la

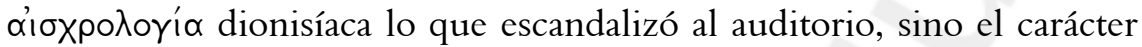
invectivo del yambo que, en la actualización del ritual poético-religioso realizado por Arquíloco, habría generado la discordia de ciertas personas que podrían haberse sentido ofendidas con la censura de sus comportamientos. Este punto de vista es interesante porque involucra al yambo en su función de భóyos, es decir, de crítica de las conductas dentro

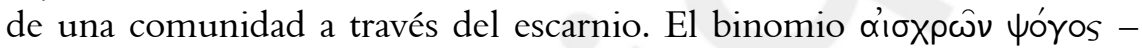
$\kappa \alpha \lambda \omega \nu$ " acciones bellas" 68 - constituía un sistema de valoración social que funcionaba fiscalizando, en épocas arcaicas, los actos cobardes y heroicos de la clase guerrera. La función ejemplarizante del elogio y de la crítica pública del individuo radica en que muchas veces la supervivencia de estos grupos comunitarios dependía del valor y de la excelencia bélica de sus integrantes. ${ }^{69}$ En épocas posteriores, con el surgimiento de la organización en torno a la polis, el incremento del intercambio comercial entre las distintas ciudades, el desarrollo técnico de la navegación comercial y militar, el advenimiento de la reforma hoplita, en fin, con todos los factores que incidieron en la consolidación de la seguridad militar de las ciudades-estados y cimentaron una vida política más activa,

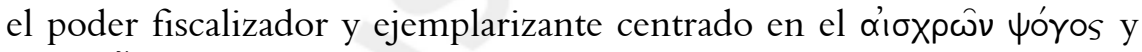

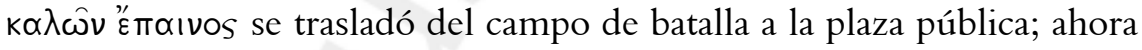
lo que comienza a enjuiciarse son las conductas de los miembros de

${ }^{67}$ Cf. Aloni, op. cit., 2009, p. 81-82.

${ }^{68}$ Plutarco, Lycurgus 8.1,6-2,8; véase Detienne, M. Los maestros de verdad en la Grecia Arcaica. Traducción bajo la dirección de Juan José Herrera. Madrid: Taurus, 1981, p. 66-76; y Nagy, G., op. cit., 1979 (ch. 12.1-2).

${ }^{69}$ Cf. Detienne, op. cit., p. 66-76. Esta práctica queda bien atestiguada en una sociedad militarizada como la antigua Esparta; en referencia a la poesía en tiempos de Licurgo

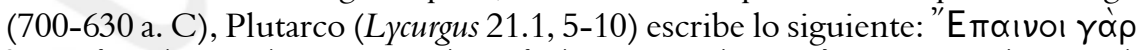

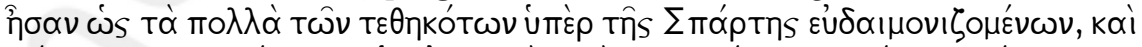

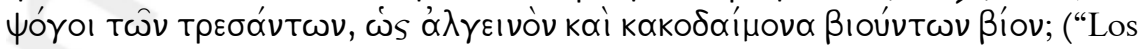
encomios eran en su mayoría de los que habían muerto por Esparta, siendo considerados dichosos, y los escarnios de los cobardes, la manera en que vivían una vida penosa y desgraciada”.). 
una comunidad en tanto ciudadanos. Como sabemos, en una civilización en que la forma de transmisión y recepción de la tradición, a través de generaciones, se arraiga aún en la oralidad, las diferentes formas poéticas hegemonizan esta función de contralor social dispensando el encomio y la censura en distintas festividades. ${ }^{70}$ Este régimen de la palabra

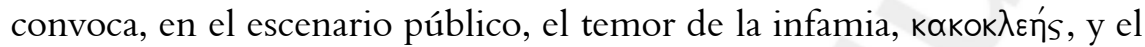
ansia de que el propio nombre quede grabado en la memoria de la

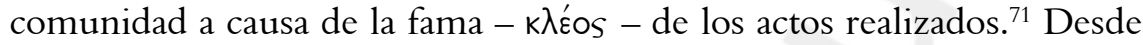
este marco, es plausible postular la ejecución poética de Arquíloco dentro

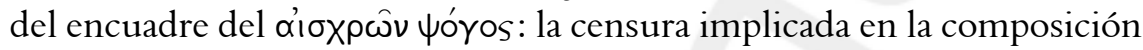
podría haber producido la ira de algunos de los habitantes de Paros. Píndaro, poeta del epinicio y paradigma del $\kappa \alpha \lambda \omega \hat{\nu}$ " una imagen de Arquíloco en su condición de crítico hostil y punzante:

es necesario que

escape a la profunda dentellada de la maledicencia.

Pues, he visto, estando distante, muchas veces en la impotencia al injurioso Arquíloco cebarse con ofensivo odio; ${ }^{72}$

Por otro lado, es relevante, como referencia para esta línea de lectura, tener en cuenta la compleja relación que el poeta contrajo con

${ }^{70}$ Principalmente en festividades y rituales religiosos como los eleusinos, los dionisíacos o las parteneas; cf. Detienne, op. cit., p. 66-67.

${ }^{71} \mathrm{El} \mathrm{\kappa \lambda} \hat{\varepsilon}^{\prime} \mathrm{OS}$ sólo existe en la cristalización que se efectúa por medio de la palabra poética; " $\mathrm{k} \lambda \varepsilon^{\prime} \mathrm{OS}$ es la gloria tal como se desarrolla de boca en boca, de generación en generación”, cf. Detienne, op. cit., 1986, p. 68. En Ilíada, XXII.304-305, Héctor, al darse cuenta que Atenea lo ha engañado tomando la forma de Deífobo y al saber que

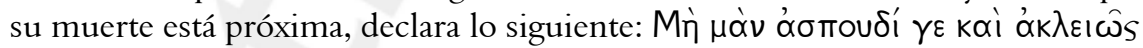

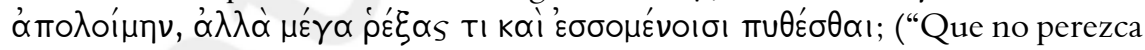
sin esfuerzo y sin gloria, sino habiendo realizado algo tan grande para que sea oído por los que han de venir".).

${ }^{72}$ Píndaro, Pítica 2.52-56:

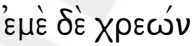

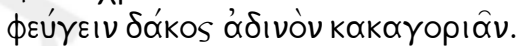

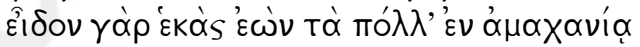

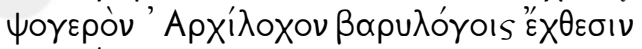

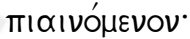

Para la interpretación del fragmento véase el interesante artículo de Miller A. Archilochus and Hieron in P. 2.52-56. Transactions of the American philological Association. Philadelphia, vol. CXI, p. 135-143, 1981. 
Licambes y sus hijas, a quienes dirigió sus versos más injuriosos. ${ }^{73} \mathrm{Si}$ bien no podemos afirmar con toda seguridad que estas personas hayan sido reales y contemporáneas de Arquíloco, ${ }^{74}$ las composiciones que los involucran nos permiten, de cualquier modo, comprender al yambo

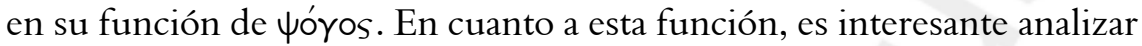
ciertas concepciones de Aristóteles en relación a lo yámbico. Primero, en Poética, al hablar sobre los orígenes de la comedia, Aristóteles afirma que el modo en que ésta tomó forma pervive únicamente en la memoria de los poetas cómicos, por tanto, no se sabe quién introdujo las máscaras, los prólogos, el número de los actores y otros detalles de este tipo $;^{75}$ sin embargo, declara que se conoce a quiénes comenzaron a componer por medio de tramas y argumentos:

pero, el componer tramas provino ciertamente, al principio, de Sicilia [Epicarmo y Fórmis], y de éstos, en Atenas, Crates [fue] el primero

${ }^{73}$ Arquíloco, ff. 30-87, 172, 188 y 196a West. Licambes fue quien acompañó a Telesicles en el viaje a Delfos; cf. "Inscripción de Mnesiepes" E1 col. II, 45, Clay.

${ }^{74}$ No intentaremos analizar, en esta instancia, el carácter ficcional o biográfico de las composiciones de Arquíloco. Existe abundante bibliografía sobre este tema: Snell B. The discovery of the mind. The Greek origins of European thought. New York: Harper, 1960; Dover, op. cit.; Merkelbach, R. Epilog des einen der Herausgeber. Zeitschrift für Papyrologie und Epigraphik. Köln, vol. XIV, p. 113. 1974; West. M. L. Studies in Greek elegy and iambus. Berlin/ New York: Walter de Gruyter, 1974; West, M. L. Archilochus ludens. Epilogue of the other editor. Zeitschrift für Papyrologie und Epigraphik. Köln, vol. XVI, p. 217-219, 1975; Lefkowitz, M. R. Fictions in literary biography: the new poem and the Archilochus legend. Arethusa. Baltimore, vol. IX, p. 181-189, 1976; Lefkowitz, M. R. The lives of the Greek poets. Baltimore: The Johns Hopkins University Press. 1981; Nagy, G. Iambos: typologies of invective and praise. Arethusa. Baltimore, vol. IX, p. 191-205, 1976; Nagy, G., op. cit., 1979; Nagy, G., op. cit., 1996; Nagy, G., op. cit., 2004; Rösler, W. Dichter und Gruppe. München: Fink, 1980; Miralles, C.; Pòrtulas, J.Archilochus and the iambic poetry. Roma: Ediz. Dell'Ateneo, 1983. Carey, C. Archilochus and Likambes. Classical Quarterly. Cambridge, vol. XXXVI, p. 60-67, 1986; Slings, S. R. (org.). The poet's I in archaic Greek lyric. Amsterdam: VU University Press, 1990; Lavigne, D. E. Iambic configurations. Iambos from Archilochus to Horace. Tesis (Doctorado en Clásicas). Stanford: Department of Classics/Stanford University, 2005. Un artículo interesante que resume y sintetiza las dos posturas frente a la interpretación de Arquíloco, sobre todo en relación al Epodo de Colonia, es el de Rösler, W. Persona reale o persona poetica? L'interpretazione dell'Io nella lirica greca. Quaderni Urbinati di Cultura Classica. Urbino, vol. XIX, p. 131-144, 1985.

${ }^{75}$ Aristóteles, Poética 5.1449b 1-5. 
que, luego de abandonar la forma yámbica, comenzó a componer argumentos y tramas universalmente. ${ }^{76}$

Dentro del ámbito retórico y literario del corpus aristotélico, la palabra ' $\delta$ śa tiene el significado concreto de "forma"77 que podría relacionarse con cierta concepción de "género literario". ${ }^{78}$ Ahora bien,

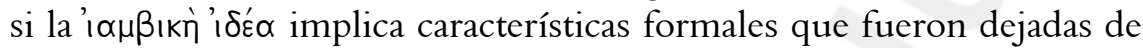
lado para dar lugar a la composición de una comedia con tramas y argumentos de tipo general o universal, sería importante preguntarnos a qué refieren estas características. En otro pasaje de Poética, Aristóteles compara la disciplina del historiador con la del poeta y afirma que el primero da cuenta de los hechos tal como sucedieron mientras que el último tal como podrían haber sucedido de acuerdo con la verosimilitud y la necesidad $;^{79}$ al explayarse sobre este tema emplea el término

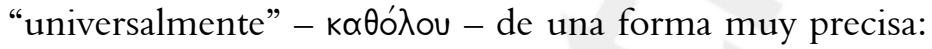

por lo cual la poesía es más filosófica y más elevada que la historia, ya que la poesía refiere más a lo universal, mientras que la historia refiere a lo individual. Y lo universal es el tipo de cosas que le corresponde decir o hacer a cierto tipo de persona según la verosimilitud o la necesidad, la poesía apunta a esto cuando otorga los nombres [a los caracteres]. ${ }^{80}$ Lo individual [es] qué hizo o qué

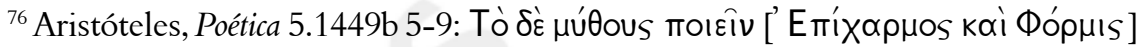

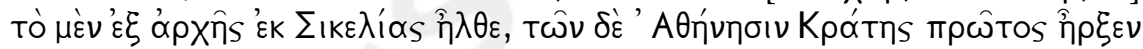

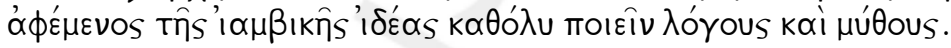

${ }^{77}$ Cf. Bonitz, H. Index Aristotelicus. Graz: Akademishe Druck/ U. Verlagsanstalt,

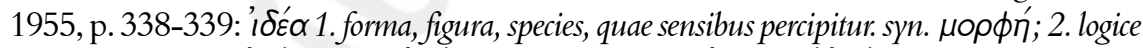

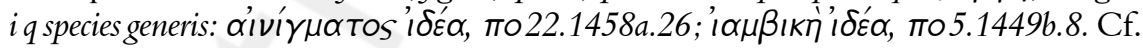
LSJ, op. cit., 817: 'ı $\delta \varepsilon \alpha$.

${ }^{78}$ Cf. Bartol, K. Greek elegy and iambus. Studies in ancient literary sources. Poznan: Uniwersytet im. Adama Mickiewicza w Poznaniu, 1993, p. 41: When referring to literary material $\eta^{\prime} \mid \delta_{\varepsilon} \alpha$ signifies the principles of composing a poem (...). Thus, the term i $\delta^{\prime} \varepsilon^{\prime} \alpha$ approximates in some way the meaning of the expression 'literary genre', as conceived by Alexandrian and later scholars.

${ }^{79}$ Aristóteles, Poética 9.1451a 36-1451b 5.

${ }^{80}$ Cf. Butcher, S. H. Aristotle's theory of poetry and fine art. New York: Dover Publications, 1951, p. 376, n. 1: The thought of the passage will be of this kind: 'It is at this universality that poetry aims when she attaches names to the characters, i.e. when instead of adopting historical names

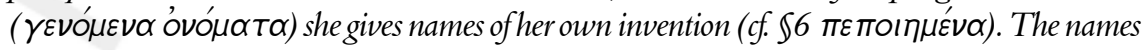
in that case are expressive; they indicate that the person is not an individual but a type. (...) The significant names of Greek Comedy fall into at least two classes: 1) Names, etymologically significant, 
experimentó Alcibíades. En la comedia esto ya es evidente: pues, luego de haber compuesto la trama, de acuerdo con lo verosímil, tan solo les ponen nombres cualesquiera [a los caracteres], y no como los poetas yámbicos que componen sobre lo individual. ${ }^{8}$

El texto de la Poética permite una lectura complementaria entre ambos pasajes. En el primero, Aristóteles manifiesta cierto contraste entre la ' $\alpha \mu \beta ı$ ก ${ }^{\prime} i \delta \varepsilon \alpha$ y la comedia en cuanto a la forma de composición que le corresponde a cada una. En la segunda cita, desarrolla el mismo esquema comparativo y sostiene, nuevamente, que la poesía (dentro de ella la comedia) posee la particularidad de construir tramas y

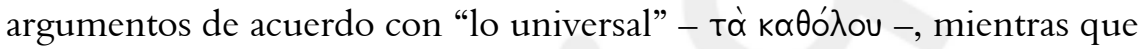
la historia y las composiciones de "los poetas yámbicos" - o i i $\alpha \mu \beta$ ßтоюо

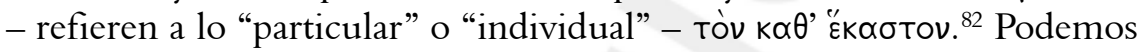
decir, entonces, que existe un paralelismo entre la comedia y su

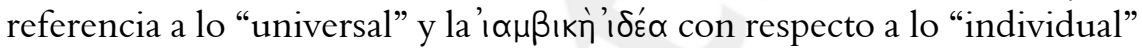
o "particular". En el mismo fragmento, Aristóteles define el carácter de universal como aquello que le corresponde decir o hacer a

such as Dicaeopolis, Euelpides, Peithetaerus, Pheidippides in the Aristophanic comedy, coexisting side by side with real names (Socrates, Cleon, etc.), which ere survival of the ' $1 \alpha \mu \beta ı \eta^{\prime}{ }^{\prime} i \delta \varepsilon$ ' $\alpha$. 2) Names which, being appropriated by usage to certain parts, designated occupation or condition,

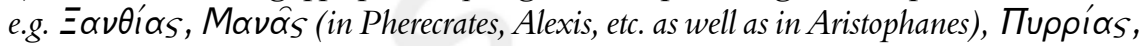
Mavía, all slave-names.

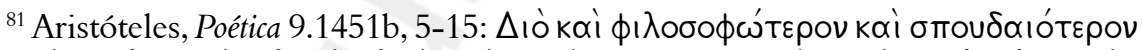

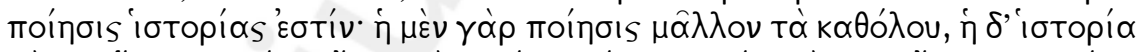

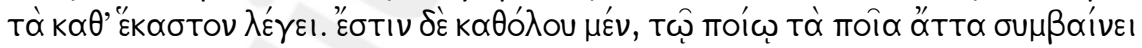

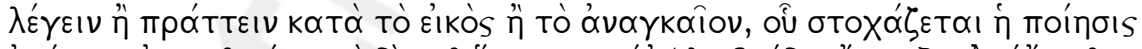

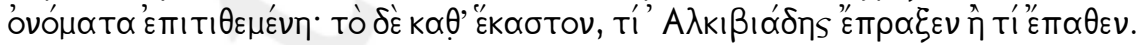

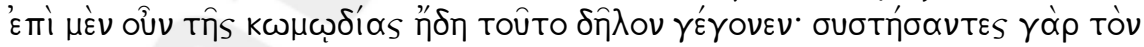

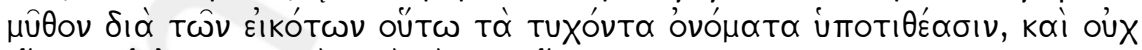

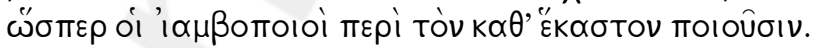

${ }^{82}$ Cf. Ferrater Mora, J. Diccionario de filosofía. Buenos Aires: Sudamericana, 1965,

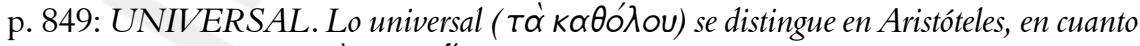
general, de lo individual ( Tòv $\kappa \alpha \theta$ ' '̌k $\alpha \sigma \tau O \nu$ ). Lo universal se refiere a una totalidad plural de objetos, con lo cual lo universal se opone a lo particular. Los juicios universales son los juicios de cantidad en los cuales el concepto-sujeto comprende la cantidad de objetos-sujetos mentados (todos $\operatorname{los} S \operatorname{son} P),(\ldots)$ y los singulares se refieren de un modo total a un objeto singular (este $S$ es $P$ ).

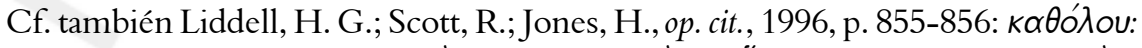
(...) in the Logic of Arist., of terms, tò K. general, opp. тò $k \alpha \theta^{\prime}$ '

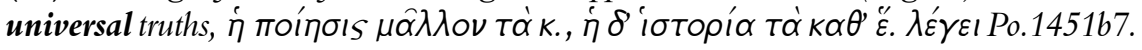


determinado tipo de persona de acuerdo con la necesidad o la verisimilitud; por el contrario, lo individual es definido como aquello que una persona en particular realizó o experimentó. ${ }^{83}$ Ahora, ambos principios operan, según sus argumentos, sobre el plano de la composición, por ende si la función - "̌pyov - del poeta no es referir los hechos que sucedieron - тஷ̀ $\gamma \varepsilon v o ́ \mu \varepsilon v \alpha$ - sino tal como podrían haber

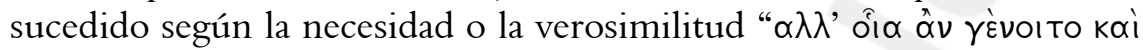

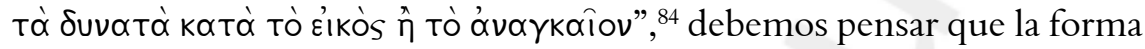
de la comedia, al igual que la de la tragedia, implica conformidad con una totalidad orgánica, es decir, una estructura ordenada en un comienzo, un medio y un fin, de tal modo que sea la causalidad la que gobierne las acciones que se desarrollan entre cada una de las partes y no la mera acumulación de componentes. ${ }^{85} \mathrm{La}$ "forma yámbica", por el contrario, carece de una estructura argumental de este tipo, ya que el yambo en sus propósitos satíricos puede hacer uso de los hechos (reales o inventados) sin necesidad de formularlos bajo la concepción de trama

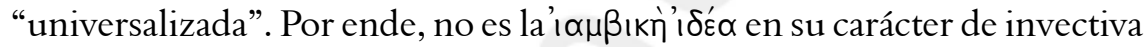
personal, con su lenguaje obsceno e insultante, sus giros cómicos, etc., lo que Crates dejó de lado, que como sabemos pervivió en la comedia, sino la forma de su composición, introduciendo tramas y argumentos que adquirieron características universales en cuanto al modo de la concatenación causal del decir y accionar de los personajes. ${ }^{86}$

Otro pasaje importante aparece en Retórica 3.17.1418b, 23-33 Kassel. Aristóteles, al hablar del carácter - 勈 - de los argumentos que se esgrimen en una deliberación o en un juicio, señala que cuando una parte quiere acusar o censurar a la otra es conveniente que lo haga

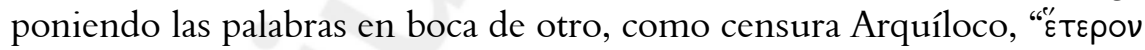

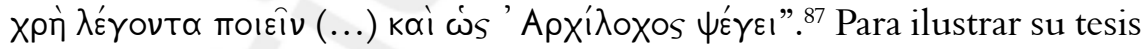
cita dos composiciones de Arquíloco: en la primera, según Aristóteles,

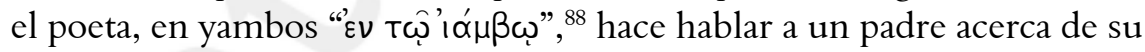

\footnotetext{
${ }^{83}$ Aristóteles, Poética 9.1451b 8-11.

${ }^{84}$ Aristóteles, Poética 9.1451a 36-38.

${ }^{85}$ Aristóteles, Poética 7.1450b 23-34.

${ }^{86}$ Cf. Heath, M. Aristotelian Comedy. Classical Quarterly. Cambridge, vol. XXXIX, p. 344-454, 1989; también, Rotstein, op. cit., p. 104-108.

${ }^{87}$ Aristóteles, Retórica 3.17.1418b, 26-27.

${ }^{88}$ Aristóteles, Retórica 3.17.1418b, 28.
} 
hija ${ }^{89}$ en la segunda, también en yambos, ${ }^{90}$ al carpintero Carón. ${ }^{91}$ Aristóteles expresa que en sus invectivas yámbicas Arquíloco disimulaba su propia identidad bajo una persona loquens, eludiendo la formulación directa de la crítica. Este artificio poético de disfraz, que podría realizarse a través de máscaras rituales-religiosas, de estereotipos de la cultura popular, "stock characters", ${ }^{92}$ o de personas reales pertenecientes al propio entorno social, parece ser el utilizado por el poeta en el "Epodo de Colonia". ${ }^{93}$ En dicha composición, un narrador presenta un diálogo entre él y la hija menor de Licambes. El interlocutor masculino incita a la joven a realizar el acto sexual, ella se niega oponiendo débiles argumentos y le ofrece a una mujer de su propia familia deseosa de

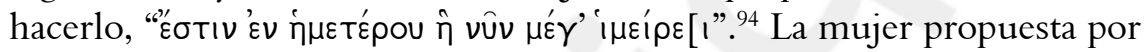
el interlocutor femenino sería su propia hermana, Neóbule, hija mayor de Licambes. La voz masculina rechaza terminantemente dicho ofrecimiento juzgando el comportamiento adúltero y libidinoso de Neóbule, y afirmando que ésta ya no está en la flor de su juventud. El diálogo termina con una nueva proposición erótica, esta vez sin oposición por parte de la joven, y con la descripción del encuentro carnal, aunque parece acordado que el acto sexual se realizaría eyaculando fuera de la vagina, coitus interruptus..$^{95}$ De este modo, no sólo queda expuesto públicamente el escarnio a la joven que, indebidamente, ha aceptado mantener relaciones con el hombre, sino también a Neóbule que es ultrajada por medio del retrato de su conducta sexual. ${ }^{96}$ Debemos considerar, entonces, que en última instancia la invectiva recae sobre Licambes, a causa del comportamiento de sus hijas. El hecho de que estos nombres puedan haber sido ficcionales no incumbe, en cierto

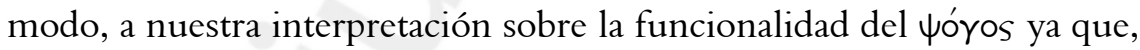
retomando las consideraciones realizadas por Aristóteles, la crítica y la

\footnotetext{
${ }^{89}$ Arquíloco, fr. 122 West.

${ }^{90}$ Aristóteles, Retórica 3.17.1418b, 30.

${ }^{91}$ Arquíloco, fr. 19 West.

${ }^{92}$ Cf. West, op. cit., 1975, p. 217.

${ }^{93}$ Arquíloco, ff. 196a, 188 West.

${ }^{94}$ Arquíloco, fr. 196a, 4-5 West.

${ }^{95}$ Arquíloco, fr. 196a, 20-25, 52-53 West.

${ }^{96}$ Varias composiciones de Arquíloco parecen referir a las hijas de Licambes, cf. 30-87 West, aunque de dispar valor, debido a la fragmentariedad de las mismos, el contenido obsceno y simposiático aparece como una constante.
} 
censura yámbica a través del enmascaramiento no deja, en última instancia, de tener un marco de referencia real en el momento de la enunciación.

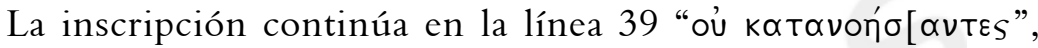

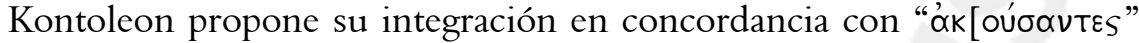
(1. 37), la incomprensión por parte del auditorio y el probable juicio

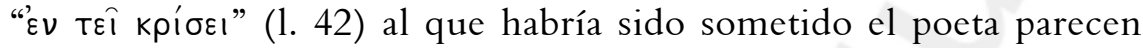

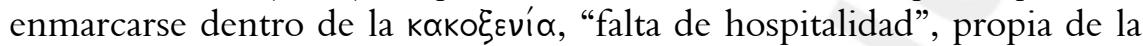
introducción del culto de Dioniso en distintas partes de Grecia. ${ }^{97}$ El hecho de que los habitantes de la isla no hayan podido comprender la nueva forma poética que Arquíloco introdujo en Paros, en su realización de invectiva con fuerte contenido obsceno, y hayan iniciado un proceso contra éste, no sólo implicaría una confrontación con la persona del poeta y su performance sino, también, una manifestación de hostilidad hacia los misterios dionisíacos. En última instancia, juzgar a Arquíloco significaría poner en tela de juicio la autoridad de Dioniso.

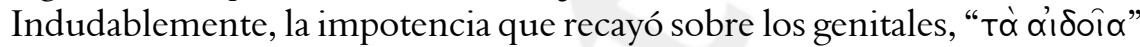
(1. 44), de los hombres de Paros fue un castigo de este dios.

En una estructura y un lenguaje similar al de la tradición de Paros, aunque con acontecimientos diferentes, un escolio a Acarnienses de Aristófanes narra la hostilidad que los atenienses manifestaron hacia el culto de Dioniso:

Pégaso de Eleuteria - Eleuteria es una ciudad de Beocia - llevando una escultura de Dioniso arribaba al Ática. Los atenienses no recibieron con honra al dios, por el contrario, luego de haber deliberado, ni siquiera le permitieron desembarcar. Por la furia del dios, una enfermedad descendió sobre los genitales de los hombres, el sufrimiento era desesperante. Como estaban cansados de que la enfermedad fuera más fuerte que todas las argucias y artes humanas, se enviaron emisarios [a Delfos] con prontitud; los que regresaron dijeron que el remedio era uno solo, si se dirigían al dios a través de toda la honra.

${ }^{97}$ Cf. Kontoleon, op. cit., 1952, p. 80-81; y Clay, op. cit., p. 19.

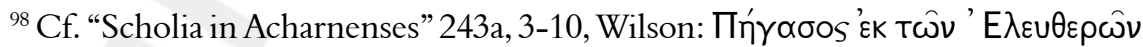

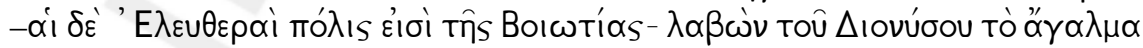

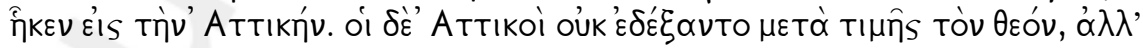

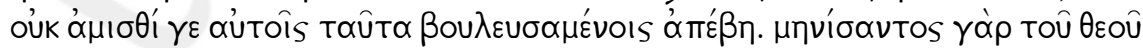

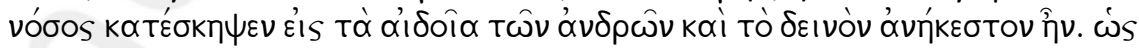

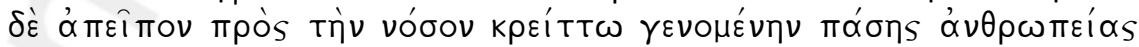

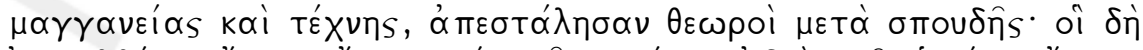

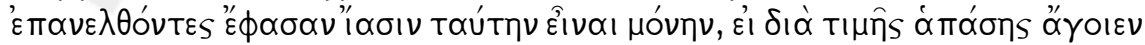
Tòv $\theta \varepsilon o ́ v$. 


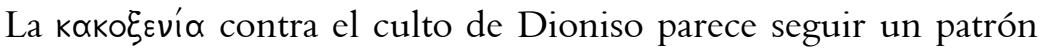
en cierto punto estipulado: a) el rechazo a la introducción de su culto por parte de los habitantes de una ciudad; b) el castigo por parte del dios: una enfermedad que afecta los genitales de los hombres; c) el envío de una delegación para consultar al oráculo de Delfos; d) la respuesta de Apolo con la orden de honrar al dios y a aquellos que introdujeron sus misterios en el lugar.

Del mismo modo, la aflicción dispensada a los hombres de la isla por las injusticias cometidas con Arquíloco tiene un fuerte paralelismo con las penas que sufrieron los ciudadanos de Delfos por haber matado a Esopo:

Esopo se burló de los habitantes de Delfos al censurarlos por esto [las faltas cometidas en los sacrificios], por esta causa muchos que se habían enfurecido, golpeándolo con piedras, lo arrojaron desde un precipicio. No mucho después, una plaga cayó sobre la ciudad; al consultar al oráculo, el dios respondió que la enfermedad no cesaría hasta que propiciaran a Esopo. Los que construyeron un muro en torno al lugar donde había caído y situaron un altar fueron expiados de la enfermedad, ya que consagraron las ofrendas al héroe. ${ }^{99}$

Si bien la muerte de Esopo no incumbe al culto de Dioniso, la cita es interesante porque, además de seguir el patrón narrativo del castigo y cura, explicita el hecho de que se le hayan consagrado ofrendas

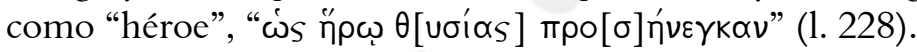

\section{Conclusión}

La "Inscripción de Mnesiepes", como testimonio de la constitución del culto heroico de Arquíloco en la isla de Paros, manifiesta la interacción entre registros del plano religioso y del plano poético. Esta comunicación dialógica, en la que el poeta se ve legitimado por la divinidad y la divinidad encuentra un medio de reproducción ritual dentro de la comunidad, instituye un relato cultural que permite leer el modo en que una sociedad elabora a través de la tradición sus lazos con

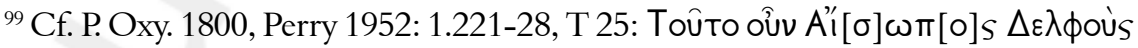

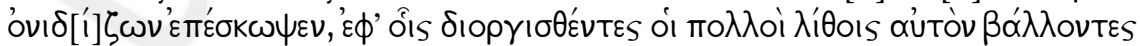

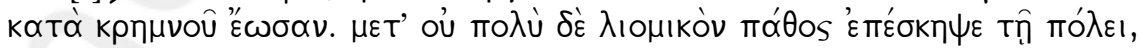

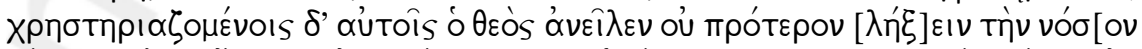

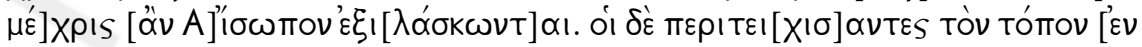

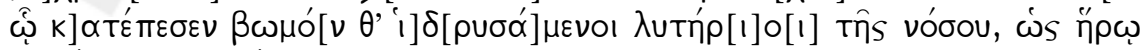

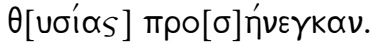


el mundo de lo religioso. Como hemos visto, este relato se caracteriza por poseer una historicidad en permanente construcción. Desde la emergencia hasta su consolidación, el culto heroico del poeta, siempre en pugna para abrirse paso como referente cultural de una comunidad, va nutriéndose de diferentes fuentes que apuntalan la justicia de su existencia; fuentes que pertenecen a la esfera de la fábula o la narración popular, de la voz divina a través de los oráculos, de la tradición literaria por medio de las referencias intertextuales, o de sucesos míticohistóricos como puede ser el patrón de la $\xi \varepsilon v i ́ \alpha$ dionisíaca. La apoteosis de Arquíloco concluye con la construcción del santuario y la exposición pública del $\mathrm{k} \lambda \varepsilon \dot{o s}$ del héroe, punto de peregrinaje del devoto, y de referencia tanto para quien busca identificarse bajo la misma colectividad como para el extranjero que sabe apreciar el valor de aquél que fue amado por los dioses. Teócrito, contemporáneo de Mnesiepes, tributa al poeta de Paros otra de las formas de la honra - тıнń - que Aristóteles considera digna de los sabios: ${ }^{100}$

Detente y observa a Arquíloco, el poeta arcaico, el de los yambos, cuya vasta fama se extendió entre la noche y el alba.

En verdad, las Musas y Apolo Delio lo amaron, tan musical e ingenioso llegó a ser al componer versos y cantar con la lira. ${ }^{101}$

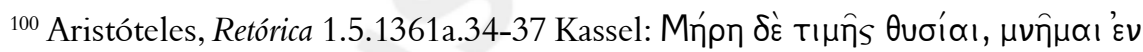

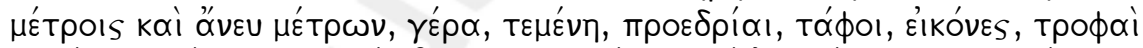

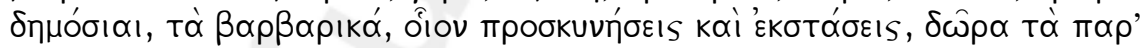

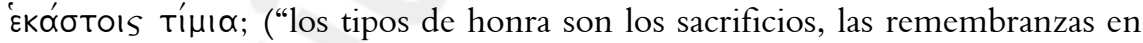
versos o con ausencia de versos, los privilegios, los santuarios, los lugares principales, los funerales públicos, las imágenes, los subsidios estatales; en cuanto a los bárbaros, tales como las prosternaciones y el hacerse a un lado, los dones son estimados en cualquier caso"). La honra más importante que recibió Arquíloco, luego de su muerte, sin duda alguna fue la construcción del témenos, sin embargo sabemos que gozó de otros honores enumerados por Aristóteles. Para las imágenes, ya sean estatuas o pinturas, remito a Clay, op cit., p. 40-62.

101 Teócrito, Anthologia Palatina 7.654 = Archilochos T 178 Tarditi:

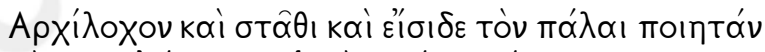

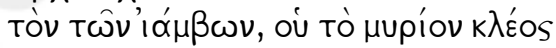

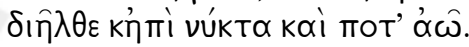

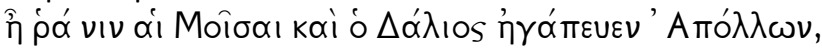

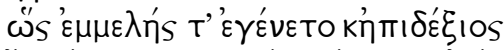

"ॄ 


\section{Referências}

ALONI, A. Poesia e biografia: Archiloco, la colonizzazione e la storia. Annali online di Ferrara. Ferrara, v. I, p. 64-103, 2009. Disponible en: < http://annali.unife.it/lettere/ 2009vol1/aloni.pdf > . Consultado el 8 de Junio de 2011.

ALONI, A.; IANNUCCI, A. L'elegia greca e l'epigrama dalle origini al $V$ secolo. Con un'appendice sulla "nuova" elegia di Archilocho. Firenze: Le Monnier, 2007.

BARTOL, K. Where was iambic poetry performed? Some evidence from the fourth century B.C. Classical Quarterly. New series. Cambridge, v. XLII, p. 65-71, 1992.

BARTOL, K. Greek elegy and iambus. Studies in ancient literary sources. Poznan: Uniwersytet im. Adama Mickiewicza w Poznaniu, 1993.

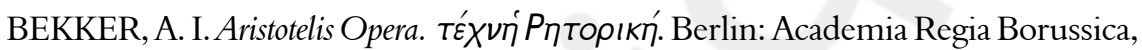
1831. T. II.

BREITENSTEIN, T. Hésiode et Archiloque. Odense (Denmark): University Press, 1971.

BROWN, C. G. Iambos. En: GERBER, D. E. (Org.). A Companion to the Greek lyric poets. Leiden: E. J. Brill, 1997. p. 11-88.

CALAME, C. Réflexions sur les genres littéraires en Grèce archaïque. Quaderni Urbinati di Cultura Classica. Urbino, v. XVII, p. 111-28, 1974.

CALAME, C. The craft of poetic speech in Ancient Greece. Traducción bajo la dirección de Janice Orion. New York: Cornell University Press, 1995.

CALAME, C. Referential fiction and poetic ritual: towards a pragmatics of myth (Sapho 17 and Bacchylides 13). Trends in Classics. Berlin, v. I, issue 1, p. 18-35, 2009.

CAREY, C. Archilochus and Likambes. Classical Quarterly. Cambridge, v. XXXVI, p. 60-67, 1986.

CHANTRAINE, P. Dictionnaire étymologique de la langue Grecque. Histoire des mots. Paris: Klincksieck, 1980.

CLAY, D. Archilochos Heros. The cult of poets in the Greek polis. Cambridge, Mass./ London: Harvard University, 2004.

COPE, E. M. An introduction to Aristotle's rhetoric. With analysis, notes and appendices. Cambridge/London: Macmillan, 1867.

DETIENNE, M. Los maestros de verdad en la Grecia Arcaica. Traducción bajo la dirección de Juan José Herrera. Madrid: Taurus, 1981.

DOVER, K. J. The poetry of Archilochos. Entretiens surl'Antiquité Classique - Archiloque. Fondation Hardt. Genève, v. X, p. 183-222. 1964.

FOWLER, R. L. The nature of early Greek lyric. Three preliminary studies. Toronto/ Buffalo/ London: University of Toronto Press, 1987.

FREESE, J. H. The Art' of Rhetoric. London-New York, 1926.

GERBER, D. E. Greek iambic poetry. From the seventh to the fifth centuries BC. Cambridge, Mass./ London: Harvard University Press, 1999. 
GIANNISI, Ph. The cows and the poet in ancient Greece. The Swedish institute in Rome. Projects and seminars. Roma, v. I, p. 125-28. 2004.

HAWKINS, T. Out-foxing the wolf-walker: Lycambes as performative rival to Archilochus. Classical Antiquity. Berkeley, v. XXVII, t. I, p. 93-114, 2008.

HENDERSON, J. The Maculate Muse. Obscene Language in Attic Comedy. New Haven: Yale University Press, 1975, p. 120-122.

KAMBYLIS, A. Zur "Dichterweihe" des Archilochos. Hermes. Wiesbaden, v. XCI, t. 2, p. 129-150.1963.

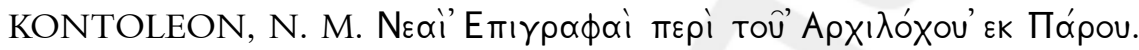
Archailogike Ephemeris. Athena, v. XCI, p. 32-95, 1952.

KONTOLEON, N. M. Archiloque d'après la nouvelle inscription de Paros. L'Hellénisme contemporain. Athène, ser. II, v. X, p. 397-406, 1956a.

KONTOLEON, N. M. Zu den neuen Archilochos Inschriften. Philologus. Berlin, v. C, p. 29-39, 1956 b.

KONTOLEON, N. M. Archilochos und Paros. Entretiens surl'Antiquité ClassiqueArchiloque. Fondation Hardt. Genéve, v. X, p. 39-86, 1964.

LAVIGNE, D. E. Iambic configurations. Iambos from Archilochus to Horace. Tesis (Doctorado en Clásicas). Stanford: Department of Classics/ Stanford University, 2005.

LEDUC, C. Sur la 'nature véritable' du mythe en Grèce ancienne. Revue de l'histoire des religions. Paris, v. CCXXI, p. 475-500, 2004.

LEHNUS, L. OІФO $\wedge \mathrm{I} \Sigma$. Alla ricerca della fonte di una glossa. Scripta Philologa, Milano, v. II, p. 159-174, 1980.

LEFKOWITZ, M. R. Fictions in literary biography: the new poem and the Archilochus Legend. Arethusa. Baltimore, v. IX, p. 181-189, 1976.

LEFKOWITZ, M. R. The lives of the Greek poets. Baltimore: The Johns Hopkins University Press. 1981.

LIDDELL, H. G.; SCOTT, R.; JONES, H. S. A Greek-English lexicon. With a revised suplement. Oxford: Clarendon Press, 1996.

MERKELBACH, R. Epilog des einen der Herausgeber. Zeitschrift für Papyrologie und Epigraphik. Köln, v. XIV, p. 113.1974.

MILLER, A. Archilochus and Hieron in P. 2.52-56. Transactions of the American philological Association. Philadelphia, v. CXI, p. 135-43, 1981.

MIRALLES, C.; PÒRTULAS, J. Archilochus and the iambic poetry. Roma: Ediz. Dell'Ateneo. 1983.

NAGY, G. Iambos: typologies of invective and praise. Arethusa. Baltimore, v. IX, p. 191-205, 1976. 
NAGY, G. The best of the Achaeans. Concepts of hero in archaic Greek poetry. Baltimore: The Johns Hopkins University Press, 1979. Disponible en: < http://www.press.jhu.edu/ books/nagy/BofA.html>. Consultado el 8 de Junio de 2011.

NAGY, G. Poetry as performance. Homer and beyond. Cambridge: University Press, 1996.

NAGY, G. Transmission of archaic Greek sympotic songs: from Lesbos to Alexandria. Critical inquiry. Chicago, v. XXXI, p. 26-48, 2004.

NOCK, A. D. Lúvvoos Oeós. Harvard studies in classical philology. Cambridge, Massachusetts: Harvard University Press, v. XLI, p. 1-62, 1930.

O'HIGGINS, L. Women and humor in Classical Greece. Cambridge: Cambridge University Press, 2003.

OLIVER, J. H. Demokratia, the gods, and the free world. Morals and law in ancient Greece. New York: Arno Press, 1979.

OHNESORG, A. Der dorische Prostylos des Archilocheion auf Paros. Archäologischer Anzieger. Berlin, p. 271-90, 1982.

PEEK, W. Neues von Archilochos. Philologus. Berlin, v. XCIX, p. 4-50, 1955.

REAL ACADEMIA ESPAÑOLA. Diccionario de la lengua española. Disponible en: < http://buscon.rae.es/draeI/>. Consultado el 8 de Junio de 2011.

RÖSLER, W. Dichter und Gruppe. München: Fink. 1980.

RÖSLER, W. Persona reale o persona poetica? L'interpretazione dell'Io nella lirica greca. Quaderni Urbinati di Cultura Classica. Urbino, v. XIX, p. 131-144, 1985.

ROTSTEIN, A. The idea of iambos. Oxford: University Press, 2010.

SLINGS, S. R. (Org.). The poet's I in archaic Greek lyric. Amsterdam: VU University Press, 1990.

SNELL, B. The discovery of the mind. The Greek origins of European thought. New York: Harper, 1960.

TARDITI, G. La nuova epigrafe archilochea e la tradizione biografica del poeta. Parola del Passato. Milano, vXI, p. 122-139, 1956.

TARDITI, G. Archilochus. Roma: Edizioni dell'Ateneo, 1968.

WEST, M. L. Hesiod. Theogony. Oxford: University Press, 1966.

WEST, M. L. Iambi et elegi Graeci ante Alexandrum cantati, I. Oxford: University Press, 1989.

WEST, M. L. Studies in Greek elegy and iambus. Berlin/ New York: Walter de Gruyter, 1974.

WEST, M. L. Archilochus ludens. Epilogue of the other editor. Zeitschrift für Papyrologie und Epigraphik. Köln, v. XVI, p. 217-19, 1975.

WILLIAMS, F. Archilochus and the eunuch: the persistence of a narrative pattern. Classics Ireland. Dublin, v. I, p. 96-112, 1994. 